\title{
GH62 arabinofuranosidases: Structure, function and applications
}

\author{
Wilkens, Casper; Andersen, Susan; Dumon, Claire; Berrin, Jean-Guy; Svensson, Birte
}

Published in:

Biotechnology Advances

Link to article, DOI:

10.1016/j.biotechadv.2017.06.005

Publication date:

2017

Document Version

Peer reviewed version

Link back to DTU Orbit

Citation (APA):

Wilkens, C., Andersen, S., Dumon, C., Berrin, J-G., \& Svensson, B. (2017). GH62 arabinofuranosidases: Structure, function and applications. Biotechnology Advances, 35, 792-804.

https://doi.org/10.1016/j.biotechadv.2017.06.005

\section{General rights}

Copyright and moral rights for the publications made accessible in the public portal are retained by the authors and/or other copyright owners and it is a condition of accessing publications that users recognise and abide by the legal requirements associated with these rights.

- Users may download and print one copy of any publication from the public portal for the purpose of private study or research.

- You may not further distribute the material or use it for any profit-making activity or commercial gain

- You may freely distribute the URL identifying the publication in the public portal

If you believe that this document breaches copyright please contact us providing details, and we will remove access to the work immediately and investigate your claim. 


\begin{abstract}
Motivated by industrial demands and ongoing scientific discoveries continuous efforts are made to identify and create improved biocatalysts dedicated to plant biomass conversion. $\alpha-1,2$ and $\alpha-1,3$ arabinofuranosyl specific $\alpha$-L-arabinofuranosidases (EC 3.2.1.55) are debranching enzymes catalyzing hydrolytic release of $\alpha$-L-arabinofuranosyl residues, which decorate xylan or arabinan backbones in lignocellulosic and pectin constituents of plant cell walls. The CAZy database classifies $\alpha$-L-arabinofuranosidases in Glycoside Hydrolase (GH) families GH2, GH3, GH43, GH51, GH54 and GH62. Only GH62 contains exclusively $\alpha$-L-arabinofuranosidases and these are of fungal and bacterial origin. Twenty-two GH62 enzymes out of 223 entries in the CAZy database have been characterized and very recently new knowledge was acquired with regard to crystal structures, substrate specificities, and phylogenetics, which overall provides novel insights into structure/function relationships of GH62. Overall GH62 $\alpha$-L-arabinofuranosidases are believed to play important roles in nature by acting in synergy with several cell wall degrading enzymes and members of GH62 represent promising candidates for biotechnological improvements of biofuel production and in various biorefinery applications.
\end{abstract}




\section{Contents}

1. Introduction

1.1 Natural substrates of GH62 $\alpha$ - L-arabinofuranosidases

1.2 Classification of $\alpha$-L-arabinofuranosidases

2. Substrate specificities and catalytic mechanism of GH62 $\alpha$-L-arabinofuranosidases

2.1 Activity on arabinoxylan and arabinoxylooligosaccharides

2.2 Activity on L-arabinan

2.3 Activity on other arabinose-containing substrates

3. GH62 $\alpha$-L-arabinofuranosidases subfamilies

4. Domains appended to GH62 $\alpha$-L-arabinofuranosidases

5. GH62 three-dimensional structures

5.1 The active-site pocket

5.2 Substrate binding subsites

5.3 A Surface binding site

6. Industrial applications of $\alpha$-L-arabinofuranosidases

7. Conclusion and outlook

Acknowledgements

References 


\section{Introduction}

Sustainable advances in plant cell wall degradation profoundly rely on carbohydrate active enzymes. Several such enzyme activities actually lag behind with regard to insight into structure/function relationships as well as biological sources of enzymes with prominent application potential. The enzymes of glycoside hydrolase family 62 (GH62), all so far being $\alpha$-Larabinofuranosidases (ABFs) (EC 3.2.1.55), belong to this category. A family GH62 enzyme was first reported in 1990 as purified from Pseudomonas fluorescens subsp. cellulosa designated xylanase C (XYLC) which released only arabinose from oat spelt xylan and is an arabinofuranosidase (Kellett el al., 1990). The specific removal by GH62 of decorations on xylan and arabinan backbones in hemicelluloses and pectins make them key for complete degradation of these polysaccharides in combination with enzymes of complementary specificities, e.g. xylanases (EC 3.2.1.8), $\beta$-xylosidases (EC 3.2.1.37), ferulic acid esterases (EC 3.1.1.73) and acetyl xylan esterases (EC 3.1.1.72). Recent progress including the first crystal structures of GH62 (see Section 5) call for an overview of current knowledge, adding importantly to the brief coverage of GH62 in the review by Laegert et al. (Lagaert et al., 2014) on $\beta$-xylosidases and ABFs accessory enzymes for arabinoxylan degradation. Clearly GH62 enzymes can increase efficacy of plant biomass conversions as a component in enzyme cocktails to be discussed at the end of the present review (see Section 6).

\subsection{Natural substrates of GH62 $\alpha$-L-arabinofuranosidases}

Plant cell walls contain substantial amounts of arabinose (Araf) in the hemicelluloses arabinoxylans (AXs) and in L-arabinan side chains of pectins (Caffall and Mohnen, 2009; Scheller and Ulvskov, 2010). AXs and L-arabinan are proven as the main targets of different ABFs of GH62 (Siguier et al., 2014; Wang et al., 2014; Wilkens et al., 2016).

AXs consist of a backbone of $\beta$-D-1,4-linked xylosyl residues (Xyl $p$ ) singly or doubly substituted with $\alpha$-L-1,2- and/or $\alpha$-L-1,3-Araf that can be further substituted by $\beta$-D-1,2-Xyl $p$ (Bowman et al., 2014) or 5-O-ferulic acid (Scheller and Ulvskov, 2010) (Fig. 1A). In more complex xylans like glucuronoarabinoxylan from corn, the $\beta$-D-1,4-Xyl $p$ backbone in addition to the above mentioned substituents is decorated by $\alpha$-L-galactose and $\alpha$-D-1,2-(4- $O$-methyl)-glucuronic acid (Rogowski et al., 2015; Scheller and Ulvskov, 2010) (Fig 1B). By contrast, L-arabinan has an $\alpha$-L-1,5-Araf backbone that is hydrolyzed by other ABFs than of GH62, but which similarly to the AXs is 
substituted singly with $\alpha$-L-1,3- as well as doubly with both $\alpha$-L-1,2-Araf and $\alpha$-L-1,3-Araf, hydrolyzed off by some GH62 enzymes (Fig. 1C) (Caffall and Mohnen, 2009).

The structural elements of the above mentioned xylans are described by a one letter code system developed by Fauré et al. (Fauré et al., 2009) where e.g. X designates an unsubstituted or terminal $\mathrm{Xyl} p$ and A a Xyl $p$ substituted with an Araf. The positions of the substitutions are indicated by superscript numbers. A plus symbol indicates that the Xyl $p$ is double substituted. Accordingly, $\mathrm{A}^{3} \mathrm{X}$ describes $\alpha$-L-Araf-( $1 \rightarrow 3)$ - $\beta$-D-Xyl $p$ - $(1 \rightarrow 4)$-D-Xyl $p$ and $\mathrm{A}^{2+3} \mathrm{X}$ describes $[\alpha$-L-Araf-( $(1 \rightarrow 2)]$ - $[\alpha$ -

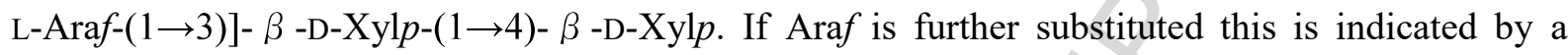
superscript number that indicates the position of the substitution and a letter indicating the type of substitution, which precedes the number indicating the position of the Araf. Lower case letters are used to designate non-glycosidic substituents. Accordingly $\mathrm{A}^{5 \mathrm{f2}}$ describes [5-O-Feruloyl]-[ $\alpha$-LAraf- $(1 \rightarrow 2)]-\beta$-D-Xylp-( $1 \rightarrow 4)$. More complex side chains are described by a combination of composite letters formed from single letters and superscript letters and numbers as above. E.g. $\mathrm{D}^{\mathrm{M} 2 \text {, }}$

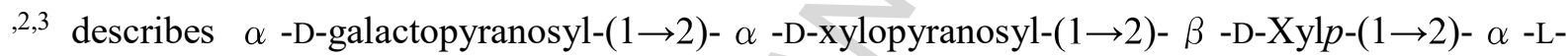
Araf-( $1 \rightarrow 3)$ - where $\mathrm{D}$ designates the $\beta$-D-Xylp-( $1 \rightarrow$ ?)- $\alpha$-L-Araf-( $(1 \rightarrow$ ?)- motif that is linked to the xylan backbone and $\mathrm{M}$ the $\alpha$-D-galactopyranosyl residue. The motifs or residues are separated by commas from the non-reducing terminal end. More examples are shown in Fig. 1.

GH62 ABFs also show limited activity on other Araf containing polysaccharides such as gum arabic, which has a $\beta$-1,3-D-galactopyranose backbone carrying $\beta$-1,6-linked galactopyranose branch chains and is substituted with $\alpha$-L-1,3-linked Araf (Street and Anderson, 1983), and pectic arabinogalactan type I that has a $\beta$-1,4-D-galactopyranose backbone substituted by $\alpha$-L-1,3-linked Araf, while type II is composed of short $\beta-1,3-$ and $\beta-1,6-\mathrm{D}-$ galactopyranose chains linked to one another via 1,3 or 1,6 branch points and substituted with $\alpha$-L-1,3- or 1,6-linked Araf (Carpita and Gibeaut, 1993). Rhamnogalacturonan is a heterogeneous part of pectin where Araf is present as Larabinan branches (Nakamura et al., 2001).

\subsection{Classification of $\alpha$-L-arabinofuranosidases}

Carbohydrate active enzymes early on were classified according to reaction mechanism and substrate specificity and given an EC number by the Enzyme Commission of the International Union of Biochemistry and Molecular Biology (IUBMB). However, in the 90's, the Carbohydrate Active enZyme database (CAZy) (www.cazy.org) started to categorize amino acid sequences of 
these enzymes, which as of today resulted in 145 glycoside hydrolase (GH) families, within each of which the members share structures and catalytic mechanism. Notably, enzymes in a given GH family can have different substrate specificities, and vice versa, the same substrate specificity can be represented in different GH families. ABFs are currently found in six GH families: GH2, GH3, GH43, GH51, GH54 and GH62 of which GH43 and GH62 share tertiary fold and constitute clan GH-F (Lombard et al., 2014).

ABFs catalyze hydrolysis of Araf from non-reducing ends of different Araf containing poly- and oligosaccharides (Margolles-Clark et al., 1996; Tagawa \& Kaji, 1969). Type A ABFs act on arabinoxylooligosaccharides (AXOS) and para-nitrophyl- $\alpha$-L-arabinofuranoside ( $p$ NPA), while type B in addition degrades polysaccharides (Vincent et al., 1997). All GH62s are active on polysaccharides, hence they are type B ABFs (Table 1). ABFs are further distinguished by their ability to release Araf from singly and doubly substituted Xylp residues (Van Laere et al., 1999). Some ABFs specifically release both 1,2- and 1,3-linked Araf from singly substituted Xyl $p$, which are given the suffix m2,3 (Lange et al., 2006; McCleary et al., 2015; Siguier et al., 2014; Van Laere et al., 1999; Wilkens et al., 2016). ABFs that release Araf from doubly substituted Xyl $p$ are specifically releasing either 1,2- or 1,3-linked Araf and are given the surfix d2 or d3, respectively (Cartmell et al., 2011; McKee et al., 2012; Pouvreau et al., 2011; Van Laere et al., 1997, 1999). None of the characterized GH62s have been shown to hydrolyze Araf from doubly substituted Xyl $p$. Enzymes in CAZy that hydrolyze polysaccharides are named after their substrate, GH family, the initials of the organism of origin and given a letter to indicate the order in which they were first reported (Henrissat et al., 1998). Hence, ABFs from GH62 are designated Abf62 and the first reported GH62 ABFs from Aspergillus nidulans and Streptomyces coelicolor are AnAbf62A and ScAbf62A, respectively.

\section{Substrate specificities and catalytic mechanism of GH62 $\alpha$-L-arabinofuranosidase}

GH62 is the sole GH family that contains only ABFs and the substrate specificity profile has been characterized for 22 enzymes of the 241 GH62 sequences (April 2017) annotated in CAZy (Table 1). The most closely related family is GH43 hosting 7479 sequences (April 2017) and several enzyme-specificities; $\beta$-xylosidase (EC 3.2.1.37); $\alpha$-L-arabinofuranosidase (EC 3.2.1.55); arabinanase (EC 3.2.1.99); xylanase (EC 3.2.1.8); galactan 1,3- $\beta$-galactosidase (EC 3.2.1.145); $\alpha$ 1,2-L-arabinofuranosidase (EC 3.2.1.-); exo- $\alpha-1,5$-L-arabinofuranosidase (EC 3.2.1.-); [inverting] exo- $\alpha-1,5$-L-arabinanase (EC 3.2.1.-); and $\beta$-1,3-xylosidase (EC 3.2.1.-) (Lombard et al., 2014; 
Mewis et al., 2016). Both A. nidulans GH62 ABF (AnAbf62A-m2,3) and Aspergillus niger GH43 1,5- $\alpha$-L-arabinanase $(A n A r b 43 A)$ were shown by NMR to use a single displacement mechanism resulting in products with inverted anomeric configuration (Pitson et al., 1996; Wilkens et al., 2016). Early biochemical assays indicated Bacillus pumilus GH43 $\beta$-D-xylosidase (BpXyn43A) to be inverting (Kersters-Hilderson et al., 1976). Notably the $\beta$-anomer of Araf was bound at the active site in the crystal structure of ScAbf62A from S. coelicolor (Maehara et al., 2014).

\subsection{Activity on arabinoxylan and arabinoxylooligosaccharides}

All characterized GH62 enzymes degraded arabinoxylans (AX) from oat spelt, wheat, and rye grains (Table 1), most enzymes having slightly higher activity on wheat AX (WAX) than on rye AX (RAX) and oat spelt xylan (OSX) (Tsujibo et al., 2002; Vincent et al., 1997; Pérez and Eyzaguirre, 2016) although two GH62 Penicillium funiculosum (syn. Talaromyces versatilis) ABFs (PfAbf62A-m2,3 and PfAbf62C-m2,3) showed 2-3 fold higher catalytic efficiency towards RAX than WAX (De La Mare et al., 2013a) due to a larger $K_{\mathrm{m}}$ for WAX (Table 1). The activity level may reflect the larger Araf content in WAX and RAX compared to OSX (Hashimoto et al., 2011; Vincent et al., 1997; Wang et al., 2014; Wilkens et al., 2016).

A. nidulans AnAbf62A-m2,3 has highest specific activity on low viscosity WAX (WAX-LV) ranging from 2.2 to 3400 fold higher compared to all characterized GH62 enzymes (Table 1). Kinetic parameters towards AX substrates for 11 GH62 enzymes from eight different species showed $K_{\mathrm{m}}$ from 0.47 to $12 \mathrm{mg} \mathrm{mL}^{-1}$ and $k_{\text {cat }}$ from 0.3 to $180 \mathrm{~s}^{-1}$ as determined under comparable assay conditions (Table 1). Notably the $k_{\mathrm{cat}}$ of $2.9 \mathrm{~s}^{-1}$ on WAX-LV for Podespora anserina GH62 $\mathrm{ABF}(P a \mathrm{Abf62A})$ and Ustilago maydis GH62 ABF (UmAbf62A-m2,3) was lower than on Larabinan (Table 1; see 2.2) (Siguier et al., 2014).

With regard to AXOS, the $S$. coelicolor ScAbf62A showed higher catalytic efficiency on $\mathrm{XA}^{3} \mathrm{X}$ (3 $\left.\mathrm{s}^{-1} \mathrm{mM}^{-1}\right)$ and $\mathrm{A}^{3} \mathrm{X}\left(0.6 \mathrm{~s}^{-1} \mathrm{mM}^{-1}\right)$ compared to $k_{\text {cat }}$ of $0.3 \mathrm{~s}^{-1}$ for WAX (Maehara et al., 2014). Streptomyces lividans GH62 ABF (SlAbf62A) had similar $V_{\max }$, but 4 fold higher $K_{\mathrm{m}}$ on OSX than WAX (Vincent et al., 1997). The specific activity of AnAbf62A-m2,3 on AXOS increased with increasing degree of polymerization (DP) being $80 \mathrm{U} \mathrm{mg}^{-1}$ ( $\mathrm{U}=$ one $\mu$ mole Ara $f$ released per min) for both a 1:1 mixture of $\mathrm{XA}^{2} \mathrm{XX}+\mathrm{XA}^{3} \mathrm{XX}$ and a 7:3 mixture of $\mathrm{A}^{2} \mathrm{XX}+\mathrm{A}^{3} \mathrm{XX}$ and only $37 \mathrm{U} \mathrm{mg}^{-1}$ for $\mathrm{A}^{3} \mathrm{X}$ (Wilkens et al., 2016). Early on product profiles indicated that SlAbf62A hydrolyzed AXOS of DP 2-6 (unknown Araf substitution patterns) (Vincent et al., 1997). ${ }^{1} \mathrm{H}$ NMR analysis showed Penicillium chrysogenum GH62 ABF (PcAbf62A-m2,3) hydrolyzed $\alpha$-L-1,3 faster than $\alpha$ - 
L-1,2 linked Araf from singly substituted Xylp in AX (Lange et al., 2006; Sakamoto et al., 2010) and that AnAbf62A-m2,3 released $\alpha-1,3$ three times faster than $\alpha-1,2$ linked Araf from a 1:1 $\mathrm{XA}^{2} \mathrm{XX}+\mathrm{XA}^{3} \mathrm{XX}$ mixture (Wilkens et al., 2016). Using different AXOS substrates ScAbf62A, PfAbf62A-m2,3 and PfAbf62C-m2,3 were demonstrated to hydrolyze singly $\alpha-1,2$ and $\alpha-1,3$ linked Araf substituents of Xylp (De La Mare et al., 2013; Maehara et al., 2014). This was seen also with WAX-HV as substrate for Streptomyces thermoviolaceus GH62 ABF (SthAbf62A-m2,3) that hydrolyzed $\alpha-1,2$ linked Araf after removal of 1,3 linked Ara from doubly substituted Xyl $p$ (Wang et al., 2014). Release of ferulic acid from AX by esterase improved accessibility for Coprinopsis cinerea GH62 ABF (CcAbf62A) to Araf substituents yielding 1.5 fold increase of the amount of reducing sugar released from AX. GH62s seemed unable to hydrolyze feruloyated Araf decorations (Hashimoto et al., 2011) and Araf substituted by $\beta-1,2$ Xylp (Bowman et al., 2015) representing sources of recalcitrance in lignocellulose. Notably, from the crystal structure $C c \mathrm{Abf} 62 \mathrm{~A}$ (see Section 5) seemed able to accommodate feruloylated Araf at subsite -1 site (Tonozuka et al., 2017) also supported by the same amount of reducing sugar being released from untreated as well as esterase-treated WAX after 8 h (EC 3.1.1.73) (Hashimoto et al., 2011).

\subsection{Activity on L-arabinan}

Nine of the 11 GH62 ABFs tested on both L-arabinan and AX showed from 9 (Couturier et al., 2011; Siguier et al., 2014) to $10^{4}$ fold (McCleary et al. 2015) lower specific activity on L-arabinan than AXs (Table 1). While the catalytic efficiency of SthAbf62A-m2,3 and AnAbf62A-m2,3 was 75 and 520 fold lower, respectively, on L-arabinan than WAXs (Tsujibo et al., 2002; Wang et al., 2014; Wilkens et al., 2016), both PaAbf62A and UmAbf62A-m2,3 had higher $k_{\text {cat }}$ on sugar beet Larabinan than on WAX (Table 1) (Siguier et al., 2014). Debranched arabinan was reported hydrolyzed with low activity by three enzymes, SlAbf62A, SthAbf62A-m2,3 and PaAbf62A (Couturier et al., 2011; Siguier et al., 2014; Tsujibo et al., 2002; Wang et al., 2014).

\subsection{Activity on other arabinose-containing substrates}

Several GH62s were tested on arabinogalactan, gum arabic and birchwood xylan (Table 1). Aspergillus sojae GH62 ABF (AsAbf62A) (Kimura et al., 2000) and AnAbf62A-m2,3 (Wilkens et al., 2016) thus hydrolyzed arabinogalactan, a specificity normally associated with GH54 (Lombard et al., 2014), albeit with much lower specific activity than on AX. Additionally AnAbf62A-m2,3 also hydrolyzed acacia tree gum arabic with very low activity (Wilkens et al., 2016). Different 
enzymes showed minimal activity for soy bean rhamnogalacturonan, birchwood and larchwood xylan and short xylooligosaccharides (Table 1).

Several GH62 members hydrolyze $p$ NPA and similar model substrates with catalytic efficiencies reported for five GH62 ABFs from 0.005 to $0.26 \mathrm{~s}^{-1} \mathrm{mM}^{-1}$ (Table 1). Trichoderma reesei GH62 ABF (TrAbf62A) had highest specific activity against $p$ NPA of $60 \mathrm{U} \mathrm{mg}^{-1}$ (Poutanen, 1988), AsAbf62A gave $18 \mathrm{U} \mathrm{mg}^{-1}$ (Kimura et al., 2000), while the other three GH62 enzymes had very low activity (Table 1). Thus, a few GH62 enzymes are reported to have very low activity on $p$ NPX (Table 1) in accordance with the general understanding that GH62s, as opposed to GH43 ABFs, lack activity activity for $\beta-1,4-X y l p$ linkages (Mewis et al., 2016).

\section{GH62 $\alpha$-L-arabinofuranosidases subfamilies}

Very recently, a study that first expanded the GH62 from 223 (December 2016) to 845 sequences by mining public databases for GH62s followed by a phylogenetic analysis yielded 18 GH62 subfamilies (Fig. 2), and a subsequent sequence motif search resulted in further subdivision of six of the subfamilies leading to a total of 27 subfamilies (Wilkens et al., 2017). The majority of the subfamilies contained members of both fungal and bacterial origin, but 9 subfamilies contain only bacterial members (GH62_1B, GH62_4, GH62_7, GH62_10B, GH62_10C, GH62_12, GH_14A, GH62_17B and GH62_18C), while GH13_A contains fungal members only (Wilkens et al., 2017). Ten of the 27 subfamilies harbor members that to some degree have been biochemically characterized, although, in most cases the biochemical characterization lacks kinetic data and/or have only been carried out using model substrates like $p$ NPA and WAX (Table 1). This is a general shortage of $\mathrm{ABF}$ characterization that hampers identifying subtle, but functionally important specificity differences between the subfamilies (Mewis et al., 2016; Wilkens et al., 2017). Only subfamilies GH62_2, GH62_8 and GH62_17A have more than one characterized member. GH62_2 is the largest subfamily with 277 members (Wilkens et al., 2017), six of which (AfAbf62A, $P c$ Abf62A-m2,3, PcaAbf62A-m2,3, ScAbf62A and SlAbf62A) are characterized (Table 1). Common for these six GH62_2 members is a very low activity towards $p$ NPA (Table 1), while the activity albeit low towards WAX and AXOS increased with the substrate length (Table 1), hence subsites beyond -1 and +1 (see section 5) are important in activity. The three GH62_2 members, PcaAbf62A-m2,3, UmAbf62A-m2,3 and ScAbf62A tested on AXOS all hydrolyzed both internal and terminal $\alpha-1,3-$ linked Araf on singly substituted Xylp (Lange et al., 2006; Maehara et al., 2014; McCleary et al., 2015). ScAfb62A displayed a catalytic efficiency three times higher on AXOS with 
internal $\alpha$-1,3-linked Araf on singly substituted Xyl $p$ compared to terminal $\alpha$-1,3-linked Araf on singly substituted Xylp (Table 1). PcaAbf62A-m2,3 was reported to hydrolyze $75 \%$ or more of both AXOS with terminal and internal $\alpha-1,3$-linked Araf on singly substituted Xyl $p$ after prolonged incubation ( $2 \mathrm{~h}$ ) (Lange et al., 2006), which not necessarily gives the right image of the regioselectivity of $P c a$ Abf62A-m2,3. PcaAbf62A-m2,3 was also shown to hydrolyze 5-25\% of the $\alpha-1,2$-linked Araf on singly substituted Xylp in AXOS (Lange et al., 2006). UmAbf62A-m2,3 preferred AXOS with internal Araf as the specific activity for $\mathrm{XA}^{3} \mathrm{XX}$ was ten times higher than for $\mathrm{A}^{3} \mathrm{X}$ (Table 1). As UmAbf62A-m2,3 displayed four times higher activity towards a 1:1 mixture of $\mathrm{XA}^{2} \mathrm{XX}$ and $\mathrm{XA}^{3} \mathrm{XX}$ than for $\mathrm{XA}^{3} \mathrm{XX}$ (Table 1) (McCleary et al., 2015) it has preference for 1,2linked Araf. This is further supported by UmAbf62A-m2,3 having higher activity for sugar beet Larabinan compared to WAX (Table 1) (Siguier et al., 2014b) as the former contains $\alpha-1,2-$ and $\alpha$ 1,3-linked Araf on singly substituted Araf (Leijdekkers et al., 2013), while the latter has only a-1,3linked Araf on singly substituted Xylp (Saulnier et al., 2007). This suggests that UmAbf62A-m2,3 prefers sugar beet L-arabinan, although it could also indicate that UmAbf62A-m2,3 in general is specific for $\alpha-1,2$-linked Araf in singly substituted Xylp/Araf (Siguier et al., 2014). Especially, because UmAbf62A-m2,3 is one of the most abundant proteins when U. maydis was grown on corn bran (Couturier et al., 2012) it may be that UmAbf62A-m2,3 is important for saccharification of the xylan fraction of corn bran.

Two GH62_8 members, Aspergillus fumigatus GH62 ABF (AfAbf62B) and Scytalidium thermophilum GH62 ABF (StAbf62A-m2,3), out of 108 have been characterized and both are active against $p$ NPA, WAX and sugar beet L-arabinan (Table 1) (Kaur et al., 2015; Pérez and Eyzaguirre, 2016). Kinetic data, however, are only reported for StAbf62A-m2,3 (Table 1) (Kaur et al., 2015), which precludes a conclusion to be drawn with respect to the favored substrate of this subfamily (Wilkens et al., 2017).

Six of the only 7 members in GH62_17A (Wilkens et al., 2017) have been characterized (Table 1). GH62_17A is extremely diverse in terms of activity (Table 1), AsAbf62A thus showing specific activity of $18 \mathrm{U} \mathrm{mg}^{-1}$ on $p$ NPA (Kimura et al., 2000) and SthAbf62A-m2,3 a $k_{\text {cat }}$ of $180 \mathrm{~s}^{-1}$ against WAX (Wang et al., 2014).

Structure based multiple alignments revealed two substrate binding areas (subsites $+2 \mathrm{R}$ and +1 , see Section 5) that vary significantly within GH62_17A. However, this was also seen for the other subfamilies with structure determined members indicating that these variations may not be related to the activity differences. Unique sequence motifs were identified for the subfamilies and the 
activity differences might be connected with these, but additional mutagenesis studies are required before a conclusion can be drawn. Additionally, these unique sequence motifs are used to distinguish subfamilies and an add-on to the program Homology To Peptide (https://sourceforge.net/projects/hotpep) allows assigning newly discovered GH62 to a subfamily (Busk et al., 2017; Wilkens et al., 2017).

Finally it should be mentioned that all four GH62_12 members lack a signal peptide indicating they are located intracellularly. Intracellular GH62s also occur in other subfamilies (Wilkens et al., 2017).

\section{Carbohydrate binding modules appended to GH62 $\alpha$-L-arabinofuranosidases}

The 845 GH62 members (see Section 3) were also analyzed for appended domains, which showed $28 \%$ being single domain enzymes. Carbohydrate binding modules (CBMs) are non-catalytic domains that bind to polysaccharides facilitating contact between catalytic domains and substrates. This interaction can both increase the hydrolysis rate for the single enzyme and the overall hydrolysis rate as the effective concentration of enzyme-substrate-complex is increased. Some CBMs are reported to disentangle the polysaccharide chains and thereby enable the enzyme substrate accessibility, while others control the direction in which the enzyme moves and ensure that the substrate is orientated correctly. In many cases these domains are essential for efficient enzymatic degradation (Boraston et al., 2004; Christiansen et al., 2009; Gilbert et al., 2013).

CBM13 is a family shown to bind to xylan when present in xylanolytic enzymes (Lombard et al., 2014) and 52\% of the GH62 members have one or two CBM13 domains (Wilkens et al., 2017). In a few cases GH62 members were linked to CBM1 (8\%), CBM2 (3\%), CBM6 (2\%), CBM22 (1\%), and CBM35 (0.1\%) (Wilkens et al., 2017), which all have been demonstrated to bind xylan and/or cellulose (Lombard et al., 2014). The large number of CBMs involved in binding to xylan suggests that GH62 enzymes are involved in xylan degradation. Notably, no CBMs were appended to members of subfamilies GH62_1C, GH62_10C, GH62_13A, GH62_13B, or GH62_12 that contains only intracellular members. Only GH62_1C has both bacterial and fungal members, while GH62_10C and GH62_12 are bacterial, and GH_13A and GH62_13B are fungal (Wilkens et al., 2017).

\section{GH62 three-dimensional structures}


Six GH62s have been structure determined, the first structures being published 2014-16 of free or carbohydrate complexed forms of some of the 22 enzymatically characterized GH62 members; $S$. thermophilum GH62 ABF (StAbf62C) (PDB ID 4PVI); S. thermoviolaceus SthAbf62A-m2,3 (PDB ID 4O8N, 408O, 4O8P), U. maydis UmAbf62A-m2,3 (PDB ID 4N1I, 4N2R), P. anserina PaAbf62A (PDB ID 4N2Z, 4N4B), C. cinerea CcAbf62A (PDB ID 5B6S), and $S$. coelicolor ScAbf62A (PDB ID 3WMY, 3WMZ, 3WN0, 3WN1, 3WN2)) (Kaur et al., 2014; Maehara et al., 2014; Siguier et al., 2014; Tonozuka et al., 2017; Wang et al., 2014). These structures share a fivebladed $\beta$-propeller fold catalytic domain where each blade has four twisted antiparallel $\beta$-strands radially orientated around a pseudo-5-fold axis (Fig. 3). The $\mathrm{N}$ - and $\mathrm{C}$-terminal blades together forms a so-called "molecular-velcro" (Kaur et al., 2014; Maehara et al., 2014; Siguier et al., 2014; Tonozuka et al., 2017; Wang et al., 2014) that occurs in nearly all $\beta$-propeller fold proteins. This circular closure is important for protein stability and some $\beta$-propeller fold proteins in addition possess a disulfide bond that connects the $\mathrm{N}$ - and C-terminal strands of the "molecular-velcro" (Jawad and Paoli, 2002; Neer and Smith, 1996) as in UmAbf62A-m2,3 (Cys10 and Cys278) (Siguier et al., 2014), ScAbf62A (Cys 176 and Cys444) (Maehara et al., 2014) and SthAbf62A-m2,3 (Cys27 and Cys297) (Wang et al., 2014). An equivalent disulfide is not present in CcAbf62A (Tonozuka et al., 2017) or in PaAbf62A where the C-terminal cysteine (Cys337) forms a disulfide bridge with Cys303 of the neighboring loop (Siguier et al., 2014).

The prominent structural differences between GH62 in loop lengths (Maehara et al., 2014; Siguier et al., 2014; Wang et al., 2014) are probably key to variation in substrate specificity as controlled by residues from the loops making up the substrate binding cleft (Wang et al., 2014). This resembles GH43 ABFs (Hassan et al., 2015; Vandermarliere et al., 2009) in which loop regions harbor specificity determinants important for conferring more or less subtle substrate specificities (Cartmell et al., 2011b; Goyal et al., 2014; McKee et al., 2012b).

Binding of xylooligosaccharides or cellooligosaccharides in GH62s did not elicit major conformational changes (Kaur et al., 2014; Maehara et al., 2014; Siguier et al., 2014; Wang et al., 2014) even though several residues involved in substrate binding in SthAbf62A-m2,3 and StAbf62A-m2,3 were observed to move (Kaur et al., 2014; Wang et al., 2014). This behavior possibly explains the ability to interact with L-arabinan, arabinogalactan, and gum arabic as well as the non-hydrolysable cellulose and $\beta$-glucan (Wang et al., 2014; Wilkens et al., 2016). L-arabinan did not fit into the binding cleft of ScAbf62A due to steric clashing as shown by molecular modeling. Indeed, ScAbf62A was confirmed not to hydrolyse L-arabinan (Maehara et al., 2014) and 
discriminated between carbohydrate structures allowing hydrolysis only of AXs. A single ScAbf62A residue, Ile308 at subsite $+2 \mathrm{NR}$ moved upon binding of xylohexaose which narrowed the entrance to the catalytic pocket (Maehara et al., 2014). Ile308 may therefore be important for substrate recognition.

\subsection{The active site pocket}

The active site topology of ABFs and other debranching enzymes was defined by Cartmell et al. (Cartmell et al., 2011) as follows: the scissile bond is between the arabinose decoration at subsite -1 (the active site) and the backbone Xyl $p$ at subsite +1 . Subsites extended toward the reducing end of the xylan backbone (from the +1 subsite) are defined as $+2 R,+3 R$ etc., whereas subsites extending toward the non-reducing end of the polymer are designated $-2 \mathrm{NR},-3 \mathrm{NR}$, and so forth (Fig. 3 and 4).

The catalytic residues are situated in a pocket that accommodates a non-reducing end single Araf at subsite -1 at the central depression of the five blades (Fig. 3 and 4) (Maehara et al., 2014; Siguier et al., 2014; Wang et al., 2014). Notably, CcAbf62A may accommodate feruloylated Araf at subsite -1 (Tonozuka et al., 2017).

In free UmAbf62A-m2,3 (PDB ID 4N1I) a water forms a hydrogen bond with O 11 of Asp36 (the putative general base catalyst) and acts as the solvent nucleophile characteristic of catalysis by inverting enzymes. During inversion of Araf from $\alpha$ - to $\beta$-configuration, Ara $f$ O1 is at the position of this water and hydrogen bonds with Asp36 O 81 . An equivalent water molecule seen in the cellotriose PaAbf62A complex further supported this role in catalysis (Siguier et al., 2014). Similarly in ScAbf62A, a water is hydrogen bonded to O $\delta 2$ of Asp202 (the putative general base catalyst) in accordance with the role in catalysis (Maehara et al., 2014). The same conclusion was made for an equivalent water in SthAbf62A-m2,3 (Wang et al., 2014). The alanine mutant of the putative general base Asp28 in AnAbf62A-m2,3 supported its role in catalysis as it showed only 1\% of the $k_{\text {cat }}$ value of wild-type; for the putative AnAbf62A-m2,3 general acid mutant Glu188Ala, $k_{\text {cat }}$ was too low to be determined (Wilkens et al., 2016). Finally, the so-called putative $\mathrm{p} K_{\mathrm{a}}$ modulator (Asp136) of the general acid catalyst seemed important for stabilizing the substrate transition state (Maehara et al., 2014) as the Asp136Ala mutant in AnAbf62A-m2,3 decreased $k_{\text {cat }}$ by $96 \%$ underlining the importance in activity (Wilkens et al., 2016). Typically, residues acting as $\mathrm{p} K_{\mathrm{a}}$ modulators also keep the general acid catalyst in the correct orientation relative to the substrate. 
Histidine in the conserved serine-histidine-glycine (SHG) motif is situated in subsite -1 at the bottom of the catalytic pocket (UmAbf62A-m2,3 H261; Fig. 4) and engaged in calcium ion coordination and hydrogen bonding with the Araf to be cleaved off (Maehara et al., 2014; Siguier et al., 2014; Tonozuka et al., 2017; Wang et al., 2014). This calcium ion found in CcAbf62A, SthAbf62A-m2,3, UmAbf62A-m2,3 and $P a A b f 62 A$ has a structural rather than a functional role as chelation by EDTA or chelex resin did not alter activity of PaAbf62A (Siguier et al., 2014; Wang et al., 2014). No calcium ion was seen in StAbf62C even though it contains the residues involved in coordination of calcium in $\mathrm{PaAbf62A}$. However, the His303Ala mutant of the corresponding histidine in StAbf62C, was completely inactive on $p$ NPAf and WAX-HV (Kaur et al., 2014).

The Araf ring is stacking with Tyr58 at subsite -1 in UmAbf62A-m2,3 (Fig. 4). Both Asp143 Oع2 (putative pKa modulator) and His261 Ne2 of the SHG motif are within hydrogen bond distance of Araf O2; Lys35 seems to hydrogen bond to Araf O4 (Siguier et al., 2014). Additional potential hydrogen bonds were identified in the ScAbf62A arabinose complex, where Araf O1 was within

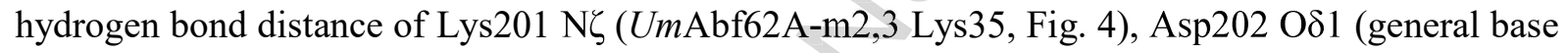
catalyst UmAbf62A-m2,3 D36, Fig. 4), Gln451 Ne2 (UmAbf62A-m2,3 Gln285, Fig. 4) and Tyr461 On (UmAbf62A-m2,3 Tyr296, Fig. 4). In ScAbf62A Araf O2 was within hydrogen bond distance of

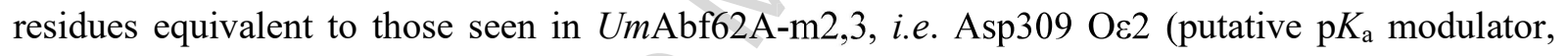
UmAbf62A-m2,3 D143, Fig. 4) and His427 Ne2 (UmAbf62A-m2,3 H261; Fig. 4) from the SHG motif, Araf O3 of Asp309 (UmAbf62A-m2,3 Asp143, Fig. 4) Oع1 and Gln269 (UmAbf62A-m2,3 Gln103, Fig. 4) N\&2, while Araf O4 was within hydrogen bond distance of Lys $201 \mathrm{~N} \zeta$ (UmAbf62A-m2,3 Lys35, Fig. 4) observed also for UmAbf62A-m2,3. Araf O5 can hydrogen bond

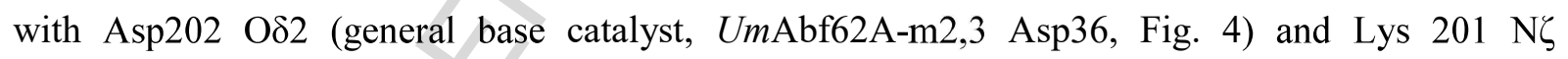
(UmAbf62A-m2,3 Lys35, Fig. 4) of ScAbf62A. Further, the Araf O5 was sequestered in a shallow hydrophobic crevice formed by Tyr224, Val251 and Trp270 in ScAbf62A, moreover the hydrophobic interaction included Ile308 and the flat face of the Araf (Fig. 4) (Maehara et al., 2014). Araf at the catalytic site pocket of SthAbf62A-m2,3 in $\alpha$-anomeric configuration participated in hydrogen bond interactions corresponding to the above mentioned conserved GH62 residues. As in ScAbf62A, a hydrophobic shallow crevice is found in SthAbf62A-m2,3 consisting of Trp111, Thr103, Ile195, and Tyr314, which, however, except for Tyr314 (UmAbf62A-m2,3 Tyr296, Fig. 4) were not conserved in GH62 (Fig. 4). Tyr314 along with Trp111 interacts with the Araf through edge-on-edge apolar contacts (Wang et al., 2014). Notably, AnAbf62A-m2,3 and SthAbf62A-m2,3 have Trp51 and Trp111, respectively at subsite -1 , whereas the equivalent residues in other GH62 
structures are tyrosine residues (Fig. 4). AnAbf62A-m2,3 and SthAbf62A-m2,3 both showed very high activity for WAX-LV compared to other GH62s (Table 1), and Trp51 (AnAbf62A-m2,3 numbering) at subsite -1 is speculated to be responsible for this exceptionally high activity (Wilkens et al. 2016).

A mutational analysis of StAbf62A-m2,3 showed that several residues, which are hydrogen bonding to Araf (His303 (UmAbf62A-m2,3 His261, Fig. 4), Lys54 (UmAbf62A-m2,3 Lys35, Fig. 4), Tyr77, Arg259 (UmAbf62A-m2,3 Arg220, Fig. 4) and Tyr338 (UmAbf62A-m2,3 Tyr296, Fig. 4)) are very important for activity as single mutants of these residues in StAbf62A-m2,3 resulted in complete loss of activity on $p$ NPA and WAX-HV (Kaur et al., 2014).

\subsection{Substrate binding subsites}

The first structural insight into subsites of GH62 was obtained for the inhibitor cellotriose $\left(K_{\mathrm{D}}=80\right.$ $\mu \mathrm{M})$ bound to $P a \mathrm{Abf} 62 \mathrm{~A}$ at subsites $+1,+2 \mathrm{R}$ and $+2 \mathrm{NR}$. Stronger binding by cellohexaose $\left(K_{\mathrm{D}}=\right.$ $12 \mu \mathrm{M}$ ) suggested the presence of additional subsites (Siguier et al., 2014). Subsites $+1,+2 \mathrm{R}$ and $+2 \mathrm{NR}$ were occupied by xylooligosaccharides in ScAbf62A (Fig. 3 and 4) and SthAbf62A-m2,3 (Kaur et al., 2014; Maehara et al., 2014; Wang et al., 2014) and additional subsites +3NR and +4NR were confirmed by complexes with xylotetraose and xylohexaose (Fig. 3 and 4) (Maehara et al., 2014; Wang et al., 2014). No further subsites were seen towards the reducing end. Remarkably, the xylan main chain bound in two orientations in ScAbf62A and SthAbf62A-m2,3, as may be required to position both single $\alpha-1,2$ - and $\alpha$-1,3-Araf in subsite -1 for productive binding in the active site pocket (Maehara et al., 2014; Wang et al., 2014).

Only subsites -1 and +1 are well conserved (Fig. 4). Varying lengths of loops that form the active site (Wang et al., 2014) and different ligand binding residues situated beyond subsites -1 and +1 may confer different GH62 substrate specificities. The diversity of these structural elements suggests GH62 adapted to interact with different types of AXs, which is also the case for GH43 ABFs where the architecture of the substrate binding cleft confers the subtle substrate specificity differences (Goyal et al., 2016).

\subsection{Surface binding site}

Carbohydrate surface binding sites (SBSs) are situated on the catalytic domain at a certain distance from the active site and have been identified in enzymes acting on different polysaccharides including xylan (Cockburn et al., 2016, 2014; Cuyvers et al., 2011). In AnAbf62A-m2,3 an SBS 
$\sim 30 \AA$ from the active site was identified by mutational analysis of Trp23 and Tyr44 (Fig. 5). The Trp23Ala, Tyr44Ala and Trp23Ala/Tyr44Ala SBS mutants did not differ dramatically in $k_{\text {cat }}$ and $K_{\mathrm{m}}$ compared to wildtype. Remarkably, however, $K_{\mathrm{i}}$ for substrate inhibition by WAX-LV of these mutants increased 4-7-fold, clearly indicating the SBS interacts with the substrate (Wilkens et al., 2016). Additionally an allosteric regulation may take place even by binding AXOS at the SBS, as the three AnAbf62A-m2,3 SBS mutants have only 4-23\% activity for AXOS compared to wildtype even though the AXOS (DP 3-5) are not long enough to cover simultaneously the active site and the SBS. Interestingly, in $C c \mathrm{Abf} 62 \mathrm{~A}$ two glycerol molecules bound close to a site equivalent to the SBS of AnAbf62A-m2,3 suggesting the presence of an SBS in CcAbf62A (Tonozuka et al., 2017). The aromatic pair Trp23 and Tyr44 of AnAbf62A-m2,3 only occurred in 7\% of the GH62 sequences (Wilkens et al., 2016), but other aromatic residues, e.g. CcAbf62A Tyr135, Tyr150 and Tyr151 are located at a position essentially corresponding to that of the SBS in AnAbf62A-m2,3. Similar aromatic residues are as well seen in PaAbf62A and StAbf62A-m2,3, suggesting they may engage in substrate binding as the SBS of AnAbf62A-m2,3 (Tonozuka et al., 2017). It is possible that occurrence of SBS in some GH62s represents an evolutionary advantage, however, mutational analysis of the SBS functional properties so far has only been carried out in AnAbf62A-m2,3.

\section{Industrial application of $\alpha$-L-arabinofuranosidases}

In Nature GH62 has been suggested to be involved in the fungal plant invasion process. GH62 members were for example upregulated in U. maydis and Magnaporthe oryzae during the plant cell wall penetration process (Lanver et al., 2014; Soanes et al., 2012). Such synergistic action involving GH62 and other xylanolytic enzymes like e.g. xylanases, $\beta$-xylosidases, ferulic acid esterases and acetyl xylan esterases illustrates the powerful role and huge potential of GH62 in industrial biotechnology. The increasing knowledge on the functional diversity of GH62 enzymes makes these attractive candidates to explore for a variety of applications.

\subsection{Biorefineries}

ABFs are important in efficient and complete degradation of plant cell wall hemicelluloses and pectin and application of ABFs has potential economic and environmental benefits in biorefineries for production of second generation bioethanol (Jordan et al., 2012). The hemicellulose fraction of feed-stock as corn and wheat straw can be highly substituted with Araf (Fig. 1) (Saha, 2003). Prior to fermentation, the hemicellulose is pre-treated by acid hydrolysis or subjected to alkali treatment 
generating non-fermentable oligosaccharide by-products inhibiting the fermentation (Saha \& Bothast, 1999). A promising alternative solution consists in enzymatic degradation of hemicelluloses using a cocktail of hemicellulolytic ABFs, xylanases, esterases and xylosidases (Harris et al., 2014), which importantly advances conversion of hemicellulose to monosaccharides (Meyer et al., 2009; Sørensen et al., 2003; Yang et al., 2014a,b). Araf and Xylp can be potent inducers for production of xylanolytic enzymes in $T$. reesei and a $T$. reesei mutant, when fed simultaneously with glucose and cellobiose gave high levels of cellulolytic and ABF activities (Ike et al., 2013). Proteome analysis of the secretome of T. reesei CL847 grown on a mixture of xylose and lactose revealed three ABFs including one GH62 (TrAbf62A) and two GH54 enzymes (Couturier et al., 2012). The same study used corn bran to induce secretion of lignocellulolytic enzymes from fungal saprotrophs. Remarkably, GH62s were among the most abundant proteins in the secretome of $U$. maydis suggesting they contribute importantly to deconstruction of plant cell wall polysaccharides (Couturier et al., 2012). A GH62 was also detected in the secretome of Fusarium verticillioides grown on maize bran (Ravalason et al., 2012) and supplementation of a $T$. reesei enzyme cocktail with these secreted enzyme mixtures improved saccharification of wheat straw (Couturier et al., 2012; Ravalason et al., 2012). For the $F$. verticillioides the increase were $24 \%, 88 \%$ and $68 \%$ for released glucose, xylose and arabinose (Ravalason et al., 2012) and for $U$. maydis the glucose release increased 22\% and total sugar release increased 57\% (Couturier et al., 2012).

Penicillum echinulatum secreted a GH62 when grown on sugar cane bagasse (Ribeiro et al., 2012). A recent transcriptomic study of $A$. niger grown on wheat straw revealed GH62s genes among those highest upregulated (Pullan et al., 2014). Another recent study showed that AXOS formed by hydrolysis of switchgrass xylan with commercial enzyme cocktails were hydrolysed by AnAbf62A$\mathrm{m} 2,3$, indicating that the AnAbf62A-m2,3 specificity is lacking in these enzyme mixtures (Bowman et al., 2015).

\subsection{Graft copolymers}

Graft copolymers consist of linear backbone with structurally different branches and one example is polystyrene. Graft copolymers differ in properties, hence also in applications, which include drug deliverer systems, plastics, textiles and many more. Polysaccharide based graft copolymers can replace some chemically synthesized graft copolymers (Bond and Bolt, 1989; Gürdag and Sarmad, 2013; Meshram et al., 2009; Thakur and Thakur, 2014). A very recent study exploited SthAbf62A- 
m2,3 in combination with $B a \mathrm{Abf} 43 \mathrm{~B}-\mathrm{d} 3$ to produce unsubstituted WAX, which increased the yield and influenced the viscoelastic properties of grafted xylans, which can be used as biobased coatings on cellulose (Littunen et al., 2017).

\subsection{Food and feed}

ABFs have been used in food production for antistaling and to improve quality of bread texture (Denli and Ercan, 2001; Jankiewicz and Michniewicz, 1987), to improve flavor and aromatic fragrance of wine (Gunata et al., 1990; Michlmayr et al., 2013; Spagna et al., 1998; Spagna, et al., 1998), and to increase solubility of precipitates and prevent haze formation in fruit juice (Whitaker, 1984). Although, no studies that apply GH62 ABFs in food and beverage production have been published it is not unthinkable that applications of GH62s can further improve the processing of cell wall derived hemicelluloses and hence the quality of the above-mentioned as well as other plantbased products.

ABFs are used to enhance animal feed digestibility (De La Mare et al., 2013b; Saha, 2000), however, ABFs are still involved in a rate limiting step in WAX degradation (De La Mare et al., 2013). De La Mare and co-workers (De La Mare et al., 2013) therefore suggested that GH62s could have potential to increase the digestibility of WAX for poultry feed.

\section{Conclusions and outlook}

In the past few years, the previously largely unnoticed GH62 family received greatly increased attention, which raised interest about its role in nature and potential valuable industrial applications. This review has therefore gathered the available recent information about functional and structural properties of characterized GH62 enzymes to provide an update and advance knowledge on their possible functional roles and performance. Notably many GH62s possess rather low specific activity towards natural substrates, but seem to have a synergistic action in biomass degradation. Differences in the subsite architecture may reflect adaptation of individual GH62 enzymes to the diverse structures of decorated xylans and arabinans, which may be explored in saccharification of plant biomass. Further investigations are required to identify their preferred substrates and coupled enzyme synergies in lignocellulytic conversions.

\section{Acknowledgments}


This work is supported by the Danish Council for Independent Research | Natural Sciences (FNU) [grant number 09-072151] (to BS) and by 1/3 PhD fellowship from the Technical University of Denmark (to $\mathrm{CW}$ ). 


\section{References}

Bond, J.A., Bolt, H.M., 1989. Review of the toxicology of styrene. CRC Crit. Rev. Toxicol. 19, 227-249. doi:10.3109/10408448909037472

Boraston, A.B., Bolam, D.N., Gilbert, H.J., Davies, G.J., 2004. Carbohydrate-binding modules: fine-tuning polysaccharide recognition. Biochem. J. 382, 769-781. doi:10.1042/BJ20040892

Bowman, M.J., Dien, B.S., Vermillion, K.E., Mertens, J.A., 2014. Structural characterization of (1$>2)$ - $\beta$-xylose-(1->3)- $\alpha$-arabinose-containing oligosaccharide products of extracted switchgrass (Panicum virgatum, L.) xylan after exhaustive enzymatic treatment with $\alpha$-arabinofuranosidase and $\beta$-endo-xylanase. Carbohydr. Res. 398, 63-71. doi:10.1016/j.carres.2014.08.006

Bowman, M.J., Dien, B.S., Vermillion, K.E., Mertens, J.A., 2015. Isolation and characterization of unhydrolyzed oligosaccharides from switchgrass (Panicum virgatum, L.) xylan after exhaustive enzymatic treatment with commercial enzyme preparations. Carbohydr. Res. 407, 42-50. doi:10.1016/j.carres.2015.01.018

Busk, P.K., Pilgaard, B., Lezyk, M., Meyer, A.S., Lange, L., 2017. Homology to Peptide Pattern for Annotation of Carbohydrate-Active Enzymes and Prediction of Function. BMC Bioinformatics 18, 214. doi:10.1186/s12859-017-1625-9

Caffall, K.H., Mohnen, D., 2009. The structure, function, and biosynthesis of plant cell wall pectic polysaccharides. Carbohydr. Res. 344, 1879-1900. doi:10.1016/j.carres.2009.05.021

Carpita, N.C., Gibeaut, D.M., 1993. Structural models of primary cell walls in flowering plants: consistency of molecular structure with the physical properties of the walls during growth. Plant J. 3, 1-30.

Cartmell, A., McKee, L.S., Peña, M.J., Larsbrink, J., Brumer, H., Kaneko, S., Ichinose, H., Lewis, R.J., Viksø-Nielsen, A., Gilbert, H.J., Marles-Wright, J., 2011. The structure and function of an arabinan-specific $\alpha-1,2$-arabinofuranosidase identified from screening the activities of bacterial GH43 glycoside hydrolases. J. Biol. Chem. 286, 15483-15495. doi:10.1074/jbc.M110.215962

Christiansen, C., Abou Hachem, M., Janecek, S., Viksø-Nielsen, A., Blennow, A., Svensson, B., 2009. The carbohydrate-binding module family 20 - diversity, structure, and function. FEBS J. 276, 5006-5029. doi:10.1111/j.1742-4658.2009.07221.x

Cockburn, D., Wilkens, C., Dilokpimol, A., Nakai, H., Lewińska, A., Abou Hachem, M., Svensson, 
B., 2016. Using Carbohydrate Interaction Assays to Reveal Novel Binding Sites in Carbohydrate Active Enzymes. PLoS One 11, e0160112. doi:10.1371/journal.pone.0160112

Cockburn, D., Wilkens, C., Ruzanski, C., Andersen, S., Willum Nielsen, J., Smith, A.M., Field, R. A., Willemoës, M., Abou Hachem, M., Svensson, B., 2014. Analysis of surface binding sites (SBSs) in carbohydrate active enzymes with focus on glycoside hydrolase families 13 and 77 — a mini-review. Biologia (Bratisl). 69, 705-712. doi:10.2478/s11756-014-0373-9

Couturier, M., Haon, M., Coutinho, P.M., Henrissat, B., Lesage-Meessen, L., Berrin, J.-G., 2011. Podospora anserina hemicellulases potentiate the Trichoderma reesei secretome for saccharification of lignocellulosic biomass. Appl. Environ. Microbiol. 77, 237-246. doi:10.1128/AEM.01761-10

Couturier, M., Navarro, D., Olivé, C., Chevret, D., Haon, M., Favel, A., Lesage-Meessen, L., Henrissat, B., Coutinho, P.M., Berrin, J.-G., 2012. Post-genomic analyses of fungal lignocellulosic biomass degradation reveal the unexpected potential of the plant pathogen Ustilago maydis. BMC Genomics 13, 57. doi:10.1186/1471-2164-13-57

Cuyvers, S., Dornez, E., Delcour, J.A., Courtin, C.M., 2011. Occurrence and functional significance of secondary carbohydrate binding sites in glycoside hydrolases. Crit. Rev. Biotechnol. 31, 93107. doi:10.3109/07388551.2011.561537

De La Mare, M., Guais, O., Bonnin, E., Weber, J., Francois, J.M., 2013. Molecular and biochemical characterization of three GH62 $\alpha$-L-arabinofuranosidases from the soil deuteromycete Penicillium funiculosum. Enzyme Microb. Technol. 53, 351-358.

doi:10.1016/j.enzmictec.2013.07.008

Denli, E., Ercan, R., 2001. Effect of added pentosans isolated from wheat and rye grain on some properties of bread. Eur. Food Res. Technol. 212, 374-376. doi:10.1007/s002170000281

Faure, R., Faulds, C.B., Fincher, E.G.B., Fort, F.S., Fry, G.S.C., Halila, S., Kabel, G.M.A, Pouvreau, K.L., Quemener, I.B., Rivet, A., Saulnier, G.L., Schols, J.H.A, Driguez, I.H., 2009. A brief and informationally rich naming system for oligosaccharide motifs of heteroxylans found in plant cell walls. Austrailan J. Chem. 62, 533-540. doi: 10.1071/CH08458

Gilbert, H.J., Knox, J.P., Boraston, A.B., 2013. Advances in understanding the molecular basis of plant cell wall polysaccharide recognition by carbohydrate-binding modules. Curr. Opin. Struct. Biol. 23, 669-677. doi:10.1016/j.sbi.2013.05.005 
Goyal, A., Ahmed, S., Fontes, C.M.G. a, Najmudin, S., 2014. Crystallization and preliminary X-ray crystallographic analysis of a novel $\alpha$-L-arabinofuranosidase (CtGH43) from Clostridium thermocellum ATCC 27405. Acta Crystallogr. Sect. F, Struct. Biol. Commun. 70, 616-6188. doi:10.1107/S2053230X14006402

Goyal, A., Ahmed, S., Sharma, K., Gupta, V., Bule, P., Alves, V.D., Fontes, C.M.G.A., Najmudin, S., 2016. Molecular determinants of substrate specificity revealed by the structure of Clostridium thermocellum arabinofuranosidase 43A from glycosyl hydrolase family 43 subfamily 16. Acta Crystallogr. Sect. D Struct. Biol. 72, 1281-1289. doi:10.1107/S205979831601737X

Gunata, Z., Brillouet, J.M., Voirin, S., Baumes, R., Cordonnier, R., 1990. Purification and some properties of an alpha.-L-arabinofuranosidase from Aspergillus niger. Action on grape monoterpenyl arabinofuranosylglucosides. J. Agric. Food Chem. 38, 772-776. doi:10.1021/jf00093a040

Gusakov, A., Punt, P., Verdoes, J., Sinitsyn, A., Vlasenko, E., Hinz, S., Gosink, M., Jiang, Z., 2007. Fungal enzymes. US7923236 B2.

Gürdag, G., Sarmad, S., 2013. Polysaccharide based graft copolymers, in: Polysaccharide Based Graft Copolymers. Springer, pp. 15-57. doi:10.1007/978-3-642-36566-9

Harris, P. V, Xu, F., Kreel, N.E., Kang, C., Fukuyama, S., 2014. New enzyme insights drive advances in commercial ethanol production. Curr. Opin. Chem. Biol. 19, 162-70. doi:10.1016/j.cbpa.2014.02.015

Hashimoto, K., Yoshida, M., Hasumi, K., 2011b. Isolation and characterization of CcAbf62A, a GH62 $\alpha$-L-arabinofuranosidase from the basidiomycete Coprinopsis cinerea. Biosci. Biotechnol. Biochem. 75, 342-345. doi:10.1271/bbb.100434

Hassan, N., Kori, L.D., Gandini, R., Patel, B.K.C., Divne, C., Tan, T.C., 2015. High-resolution crystal structure of a polyextreme GH43 glycosidase from Halothermothrix orenii with $\alpha$-Larabinofuranosidase activity. Acta Crystallogr. Sect. F- Struct. Biol. Commun. 71, 338-345. doi:10.1107/S2053230X15003337

Ike, M., Park, J., Tabuse, M., Tokuyasu, K., 2013. Controlled preparation of cellulases with xylanolytic enzymes from Trichoderma reesei (Hypocrea jecorina) by continuous-feed cultivation using soluble sugars. Biosci. Biotechnol. Biochem. 77, 161-166. 
doi:10.1271/bbb.120696

Jankiewicz, M., Michniewicz, J., 1987. The effect of soluble pentosans isolated from rye grain on staling of bread. Food Chem. 25, 241-249. doi:10.1016/0308-8146(87)90010-0

Jawad, Z., Paoli, M., 2002. Novel sequences propel familiar folds. Structure, 10, 447-454. doi: 10.1016/S0969-2126(02)00750-5

Jordan, D.B., Bowman, M.J., Braker, J.D., Dien, B.S., Hector, R.E., Lee, C.C., Mertens, J.A, Wagschal, K., 2012. Plant cell walls to ethanol. Biochem. J. 442, 241-52. doi:10.1042/BJ20111922

Kaur, A.P., Nocek, B.P., Xu, X., Lowden, M.J., Leyva, J.F., Stogios, P.J., Cui, H., Di Leo, R., Powlowski, J., Tsang, A., Savchenko, A., 2014b. Functional and structural diversity in GH62 $\alpha$-L-arabinofuranosidases from the thermophilic fungus Scytalidium thermophilum. Microb. Biotechnol. 8, 419-433. doi:10.1111/1751-7915.12168

Kellett, L.E., Poole, D.M., Ferreira, L.M., Durrant, a J., Hazlewood, G.P., Gilbert, H.J., 1990. Xylanase B and an arabinofuranosidase from Pseudomonas fluorescens subsp. cellulosa contain identical cellulose-binding domains and are encoded by adjacent genes. Biochem. J. 272, 369-376. doi: 10.1042/bj2720369

Kersters-Hilderson, H., Claeyssens, M., van Doorslaer, E., de Bruyne, C.K., 1976. Determination of the anomeric configuration of D-xylose with D-xylose isomerases. Carbohydr. Res. 47, 269273.

Kimura, I., Yoshioka, N., Kimura, Y., Tajima, S., 2000. Cloning, sequencing and expression of an $\alpha$-L-arabinofuranosidase from Aspergillus sojae. J. Biosci. Bioeng. 89, 262-266. doi: $10.1016 / \mathrm{S} 1389-1723(00) 88830-1$

Lagaert, S., Pollet, A., Courtin, C.M., Volckaert, G., 2014. $\beta$-xylosidases and $\alpha$-Larabinofuranosidases: accessory enzymes for arabinoxylan degradation. Biotechnol. Adv. 32, 316-332. doi:10.1016/j.biotechadv.2013.11.005

Lange, L., Sørensen, H.R., Hamann, T., 2006. Penicillium capsulatum arabinofuranosidase. WO2006125438.

Lanver, D., Berndt, P., Tollot, M., Naik, V., Vranes, M., Warmann, T., Münch, K., Rössel, N., Kahmann, R., 2014. Plant surface cues prime Ustilago maydis for biotrophic development. PLoS Pathog. 10, e1004272. doi:10.1371/journal.ppat.1004272 
Laothanachareon, T., Bunterngsook, B., Suwannarangsee, S., Eurwilaichitr, L., Champreda, V., 2015. Synergistic action of recombinant accessory hemicellulolytic and pectinolytic enzymes to Trichoderma reesei cellulase on rice straw degradation. Bioresour. Technol. 198, 682-690. doi:10.1016/j.biortech.2015.09.053

Leijdekkers, A.G.M., Bink, J.P.M., Geutjes, S., Schols, H.A., Gruppen, H., 2013. Enzymatic saccharification of sugar beet pulp for the production of galacturonic acid and arabinose; a study on the impact of the formation of recalcitrant oligosaccharides. Bioresour. Technol. 128, 518-525. doi:10.1016/j.biortech.2012.10.126

Littunen, K., Mai-Gisondi, G., Seppälä, J., Master, E.R., 2017. Enzymatically debranched xylans in graft copolymerization. Biomacromolecules 18, 1634-1641. doi:10.1021/acs.biomac.7b00229

Lombard, V., Golaconda Ramulu, H., Drula, E., Coutinho, P.M., Henrissat, B., 2014. The carbohydrate-active enzymes database (CAZy) in 2013. Nucleic Acids Res. 42, D490-495. doi:10.1093/nar/gkt1178

Maehara, T., Fujimoto, Z., Ichinose, H., Michikawa, M., Harazono, K., Kaneko, S., 2014. Crystal structure and characterization of the glycoside hydrolase family $62 \alpha$-L-arabinofuranosidase from Streptomyces coelicolor. J. Biol. Chem. 289, 7962-7972. doi:10.1074/jbc.M113.540542

Margolles-Clark, E., Tenkanen, M., Nakari-Setälä, T., Penttilä, M., 1996. Cloning of genes encoding $\alpha$-L-arabinofuranosidase and $\beta$-xylosidase from Trichoderma reesei by expression in Saccharomyces cerevisiae. Appl. Environ. Microbiol. 62, 3840-3846.

McCleary, B. V., McKie, V.A., Draga, A., Rooney, E., Mangan, D., Larkin, J., 2015. Hydrolysis of wheat flour arabinoxylan, acid-debranched wheat flour arabinoxylan and arabino-xylooligosaccharides by $\beta$-Xylanase, $\alpha$-L-arabinofuranosidase and $\beta$-xylosidase. Carbohydr. Res. 407, 79-96. doi:10.1016/j.carres.2015.01.017

McKee, L.S., Peña, M.J., Rogowski, A., Jackson, A., Lewis, R.J., York, W.S., Krogh, K.B.R.M., Viksø-Nielsen, A., Skjøt, M., Gilbert, H.J., Marles-Wright, J., 2012. Introducing endoxylanase activity into an exo-acting arabinofuranosidase that targets side chains. PNAS 109, 6537-6542. doi:10.1073/pnas.1117686109

Meshram, M.W., Patil, V. V., Mhaske, S.T., Thorat, B.N., 2009. Graft copolymers of starch and its application in textiles. Carbohydr. Polym. 75, 71-78. doi:10.1016/j.carbpol.2008.06.012

Mewis, K., Lenfant, N., Lombard, V., Henrissat, B., 2016. Dividing the large glycoside hydrolase 
family 43 into subfamilies: A motivation for detailed enzyme characterization. Appl. Environ. Microbiol. 82, 1686-1692. doi:10.1128/AEM.03453-15

Meyer, A.S., Rosgaard, L., Sørensen, H.R., 2009. The minimal enzyme cocktail concept for biomass processing. J. Cereal Sci. 50, 337-344. doi:10.1016/j.jcs.2009.01.010

Neer, E.J., Smith, T.F., 1996. G Protein heterodimers: New structures propel New Questions. Cell 84, 175-178. doi:10.1016/S0092-8674(00)80969-1

Pérez, R., Eyzaguirre, J., 2016. Aspergillus fumigatus produces two arabinofuranosidases from glycosyl hydrolase family 62: Comparative properties of the recombinant enzymes. Appl. Biochem. Biotechnol. 179, 143. doi:10.1007/s12010-016-1984-0

Pitson, S.M., Voragen, A.G., Beldman, G., 1996. Stereochemical course of hydrolysis catalyzed by arabinofuranosyl hydrolases. FEBS Lett. 398, 7-11. doi: 10.1016/S0014-5793(96)01153-2

Poutanen, K., 1988. An $\alpha$-L-arabinofuranosidase of Trichoderma reesei. J. Biotechnol. 7, 271-281. doi:10.1016/0168-1656(88)90039-9

Pouvreau, L., Joosten, R., Hinz, S.W.A., Gruppen, H., Schols, H.A., 2011. Chrysosporium lucknowense $\mathrm{C} 1$ arabinofuranosidases are selective in releasing arabinose from either single or double substituted xylose residues in arabinoxylans. Enzyme Microb. Technol. 48, 397-403. doi:10.1016/j.enzmictec.2011.01.004

Pullan, S.T., Daly, P., Delmas, S., Ibbett, R., Kokolski, M., Neiteler, A., van Munster, J.M., Wilson, R., Blythe, M.J., Gaddipati, S., Tucker, G.A., Archer, D.B., 2014. RNA-sequencing reveals the complexities of the transcriptional response to lignocellulosic biofuel substrates in Aspergillus niger. Fungal Biol. Biotechnol. 1, 3. doi:10.1186/s40694-014-0003-x

Ransom, R.F., Walton, J.D., 1997. Purification and characterization of extracellular $\beta$-xylosidase and $\alpha$-arabinosidase from the plant pathogenic fungus Cochliobolus carbonum. Carbohydr. Res. 297, 357-364. doi: 10.1016/S0008-6215(96)00281-9

Ravalason, H., Grisel, S., Chevret, D., Favel, A., Berrin, J.-G., Sigoillot, J.-C., Herpoël-Gimbert, I., 2012. Fusarium verticillioides secretome as a source of auxiliary enzymes to enhance saccharification of wheat straw. Bioresour. Technol. 114, 589-96. doi:10.1016/j.biortech.2012.03.009

Ribeiro, D.A., Cota, J., Alvarez, T.M., Brüchli, F., Bragato, J., Pereira, B.M.P., Pauletti, B.A., Jackson, G., Pimenta, M.T.B., Murakami, M.T., Camassola, M., Ruller, R., Dillon, A.J.P., 
Pradella, J.G.C., Paes Leme, A.F., Squina, F.M., 2012. The Penicillium echinulatum secretome on sugar cane bagasse. PLoS One 7. doi:10.1371/journal.pone.0050571

Rogowski, A., Briggs, J.A., Mortimer, J.C., Tryfona, T., Terrapon, N., Lowe, E.C., Baslé, A., Morland, C., Day, A.M., Zheng, H., Rogers, T.E., Thompson, P., Hawkins, A.R., Yadav, M.P., Henrissat, B., Martens, E.C., Dupree, P., Gilbert, H.J., Bolam, D.N., 2015. Glycan complexity dictates microbial resource allocation in the large intestine. Nat. Commun. 6, 7481. doi:10.1038/ncomms8481

Saha, B.C., 2003. Hemicellulose bioconversion. J. Ind. Microbiol. Biotechnol. 30, 279-291. doi:10.1007/s10295-003-0049-x

Saha, B.C., 2000. $\alpha$-L-arabinofuranosidases: biochemistry, molecular biology and application in biotechnology. Biotechnol. Adv. 18, 403-423. Doi : 10.1016/S0734-9750(00)00044-6

Saha, B.C., Bothast, R.J., 1999. Pretreatment and enzymatic saccharification of corn fiber. Appl. Biochem. Biotechnol. 76, 65-77. doi:10.1385/ABAB:76:2:65

Sakamoto, T., Ogura, A., Inui, M., Tokuda, S., Hosokawa, S., Ihara, H., Kasai, N., 2010. Identification of a GH62 $\alpha$-L-arabinofuranosidase specific for arabinoxylan produced by Penicillium chrysogenum. Appl. Microbiol. Biotechnol. 90, 137-146. doi:10.1007/s00253010-2988-2

Saulnier, L., Sado, P.E., Branlard, G., Charmet, G., Guillon, F., 2007. Wheat arabinoxylans: Exploiting variation in amount and composition to develop enhanced varieties. J. Cereal Sci. 46, 261-281. doi:10.1016/j.jcs.2007.06.014

Scheller, H.V., Ulvskov, P., 2010. Hemicelluloses. Annu. Rev. Plant Biol. 61, 263-89. doi:10.1146/annurev-arplant-042809-112315

Siguier, B., Haon, M., Nahoum, V., Marcellin, M., Burlet-Schiltz, O., Coutinho, P.M., Henrissat, B., Mourey, L., O Donohue, M.J., Berrin, J.-G., Tranier, S., Dumon, C., 2014. First structural insights into $\alpha$-L-arabinofuranosidases from the two GH62 glycoside hydrolase subfamilies. J. Biol. Chem. 289, 5261-5273. doi:10.1074/jbc.M113.528133

Soanes, D.M., Chakrabarti, A., Paszkiewicz, K.H., Dawe, A.L., Talbot, N.J., 2012. Genome-wide transcriptional profiling of appressorium development by the rice blast fungus Magnaporthe oryzae. PLoS Pathog. 8. doi:10.1371/journal.ppat.1002514

Spagna, G., Romagnoli, D., Angela, M., Bianchi, G., Pifferi, P.G., 1998a. A simple method for 
purifying glycosidases : $\alpha$-L-arabinofuranosidase and $\beta$-D-glucopyranosidase from Aspergillus niger to increase the aroma of wine . Part I. Enzyme Microb. Technol. 22, 298-304. doi:10.1016/S0141-0229(97)00141-5

Spagna, G., Andreani, F., Salatelli, E., Romagnoli, D., Casarini, D., Pifferi, P.G., 1998b. Immobilization of the glycosidases : $\alpha$-L-arabinofuranosidase and $\beta$-D-glucopyranosidase from Aspergillus niger on a chitosan derivative to increase the aroma of wine . Part II. Enzyme Microb. Technol. 23, 413-421. doi:10.1016/S0141-0229(97)00249-4

Street, C. A. and Anderson, D. M. (1983) Refinement of structures previously proposed for gum arabic and other acacia gum exudates. Talanta. 30, 887-893

Sørensen, H.R., Meyer, A.S., Pedersen, S., 2003. Enzymatic hydrolysis of water-soluble wheat arabinoxylan. 1. Synergy between $\alpha$-L-arabinofuranosidases, endo-1,4- $\beta$-xylanases, and $\beta$ xylosidase activities. Biotechnol. Bioeng. 81, 726-731. doi:10.1002/bit.10519

Tagawa, K., Kaji, A., 1969. Preparation of L-arabinose-containing polysaccharides and the action of an $\alpha$-L-arabinofuranosidase on these polysaccharides. Carbohydr. Res. 11, 293-301. doi:10.1016/S0008-6215(00)80570-4

Thakur, V.K. and Thakur M.K.,, 2014. Recent advance in graft copolymerization and application of chitosan: A review. ACS Sustain. Chem. Eng 2, 2637-2652. doi:10.1021/sc500634p

Tonozuka, T., Tanaka, Y., Okuyama, S., Miyazaki, T., Nishikawa, A., Yoshida, M., 2017. Structure of the catalytic domain of $\alpha$-L-arabinofuranosidase from Coprinopsis cinerea, CcAbf62A, provides insights into structure-function relationships in glycoside hydrolase Family 62. Appl. Biochem. Biotechnol. 181, 511-525 doi:10.1007/s12010-016-2227-0

Tsujibo, H., Takada, C., Wakamatsu, Y., Kosaka, M., Tsuji, A., Miyamoto, K., Inamori, Y., 2002. Cloning and expression of an $\alpha$-L-arabinofuranosidase gene (stxIV) from Streptomyces thermoviolaceus OPC-520, and characterization of the enzyme. Biosci. Biotechnol. Biochem. 66, 434-438. doi:10.1271/bbb.66.434

Van Laere, K.M., Beldman, G., Voragen, A.G., 1997. A new arabinofuranohydrolase from Bifidobacterium adolescentis able to remove arabinosyl residues from double-substituted xylose units in arabinoxylan. Appl. Microbiol. Biotechnol. 47, 231-235.

Van Laere, K.M.J., Voragen, C.H.L., Kroef, T., Van den Broek, L.A.M., Beldman, G., Voragen, A.G.J., 1999. Purifcation and mode of action of two different arabinoxylan 
arabinofuranohydrolases from Bifidobacterium adolescentis DSM 20083. Appl. Microbiol. Biotechnol. 51, 606-613.

Vandermarliere, E., Bourgois, T.M., Winn, M.D., van Campenhout, S., Volckaert, G., Delcour, J. a, Strelkov, S. V, Rabijns, A., Courtin, C.M., 2009. Structural analysis of a glycoside hydrolase family 43 arabinoxylan arabinofuranohydrolase in complex with xylotetraose reveals a different binding mechanism compared with other members of the same family. Biochem. J. 418, 39-47. doi:10.1042/BJ20081256

Vincent, P., Shareck, F., Dupont, C., Morosoli, R., Kluepfel, D., 1997. New $\alpha$-Larabinofuranosidase produced by Streptomyces lividans: cloning and DNA sequence of the abfB gene and characterization of the enzyme. Biochem. J. 322, 845-852.

Wang, W., Mai-Gisondi, G., Stogios, P.J., Kaur, A., Xu, X., Cui, H., Turunen, O., Savchenko, A., Master, E.R., 2014. Elucidation of the molecular basis for arabinoxylan-debranching activity of a thermostable family GH62 $\alpha$-L-arabinofuranosidase from Streptomyces thermoviolaceus. Appl. Environ. Microbiol. 80, 5317-29. doi:10.1128/AEM.00685-14

Whitaker, J.R., 1984. Pectic substances, pectic enzymes and haze formation in fruit juices. Enzyme Microb. Technol. 6, 341-349. doi:10.1016/0141-0229(84)90046-2

Wilkens, C., Lange, L., Busk, P.K., 2017. Phylogenetic analysis of expanded glycoside hydrolase family 62: A guide for future structure-function studies of the family potentially important for saccharification of recalcitrant biomass. Front. Bioeng. Biotechnol., in review

Wilkens, C., Andersen, S., Petersen, B.O., Birch, J., Li, A., Busse-Wicher, M., Cockburn, D., Nakai, H., Christensen, H.E.M., Dupree, P., McCleary, B., Kragelund, B.B., Hindsgaul, O., Abou Hachem, M., Svensson, B., 2016. An efficient arabinoxylan-debranching $\alpha$-Larabinofuranosidase of family GH62 from Aspergillus nidulans contains a secondary carbohydrate binding site. Appl. Microbiol. Biotechnol. 100, 6265-6277.

Yang, X., Shi, P., Huang, H., Luo, H., Wang, Y., Zhang, W., Yao, B., 2014a. Two xylose-tolerant GH43 bifunctional $\beta$-xylosidase/ $\alpha$ - arabinosidases and one GH11 xylanase from Humicola insolens and their synergy in the degradation of xylan. Food Chem. 148, 381-387. doi:10.1016/j.foodchem.2013.10.062

Yang, X., Shi, P., Ma, R., Luo, H., Huang, H., Yang, P., Yao, B., 2014b. A New GH43 $\alpha-$ arabinofuranosidase from Humicola insolens $\mathrm{Y} 1$ : Biochemical characterization and synergistic 
action with a xylanase on xylan degradation. Appl. Biochem. Biotechnol. 175, 1960-1970. doi:10.1007/s12010-014-1416-y 


\section{Figure legends}

Fig. 1: Schematic structures of A) arabinoxylan, B) corn glucuronoarabinoxylan, C) L-arabinan and D) nomenclature as used for these in the text. The one letter code system developed by Fauré et al. (Fauré et al., 2009) is used to describe the arabinoxylan and corn glucuronoarabinoxylan, and has been expanded to the L-arabinan.

Fig. 2: Phylogenetic tree of glycoside hydrolase family 62. The 18 subfamilies are distinguish by their colors. After (Wilkens et al., 2017)

Fig. 3: 3D structure of $S c$ Abf62A in complex with xylopentaose (cyan) (PDB ID 3WN2). Subsites are labelled according to McKee et al. (McKee et al., 2012b).

Fig. 4: Subsites and side chains shown to interact with xylooligosaccharides in crystal structures of GH62. Side chains invariant among the six GH62 structures are shown in grey, while the noninvariant are coloured as: UmAbf62A-m2,3 (PDB ID 4N2R) (green), SthAbf62A-m2,3 (PDB ID 4O8O) (pink), StAbf62C (PDB ID 4PVI) (brown), ScAbf62A (PDB ID 3WN2) (yellow), CcAbf62A (PDB ID 5B6S) (blue) and PaAbf62A (PDB ID 4N2Z) (salmon). Xylopentaose (cyan) from $S c$ Abf62A (PDB ID 3WN2) and arabinose (orange) from SthAbf62A-m2,3 (PDB ID 4O8O) are shown. Numbering of the invariant residues refers to UmAbf62A-m2,3.

Fig. 5: 3D homology model of AnAbf62A-m2,3 indicating the position of the residues involved in binding at the surface binding site (SBS) (green) and subsite -1 where putative catalytic residues are shown (orange). 


\section{Table legends}

Table 1: Substrate specificity and kinetic data of GH62 enzymes. AX: arabinoxylan, MUF: 4methylumbelliferyl, $\mathrm{n} / \mathrm{a}$ : not available, $p \mathrm{NP}$ : para-nitrophenol, $p \mathrm{NP}-\mathrm{A}$ : para-nitrophenyl $\alpha$-Larabinofuranoside, $p$ NP-X: para-nitrophenyl $\beta$-D-xylopyranoside, Sp. act.: Specific activity, U: unit defined as the release of $1 \mu \mathrm{mol}$ of product per min under the specific assay conditions, arabinoxylooligosaccharides named according to (Faure et al., 2009). *: values are normalized according to the unit; ${ }^{* *}$ : accession no. not available.

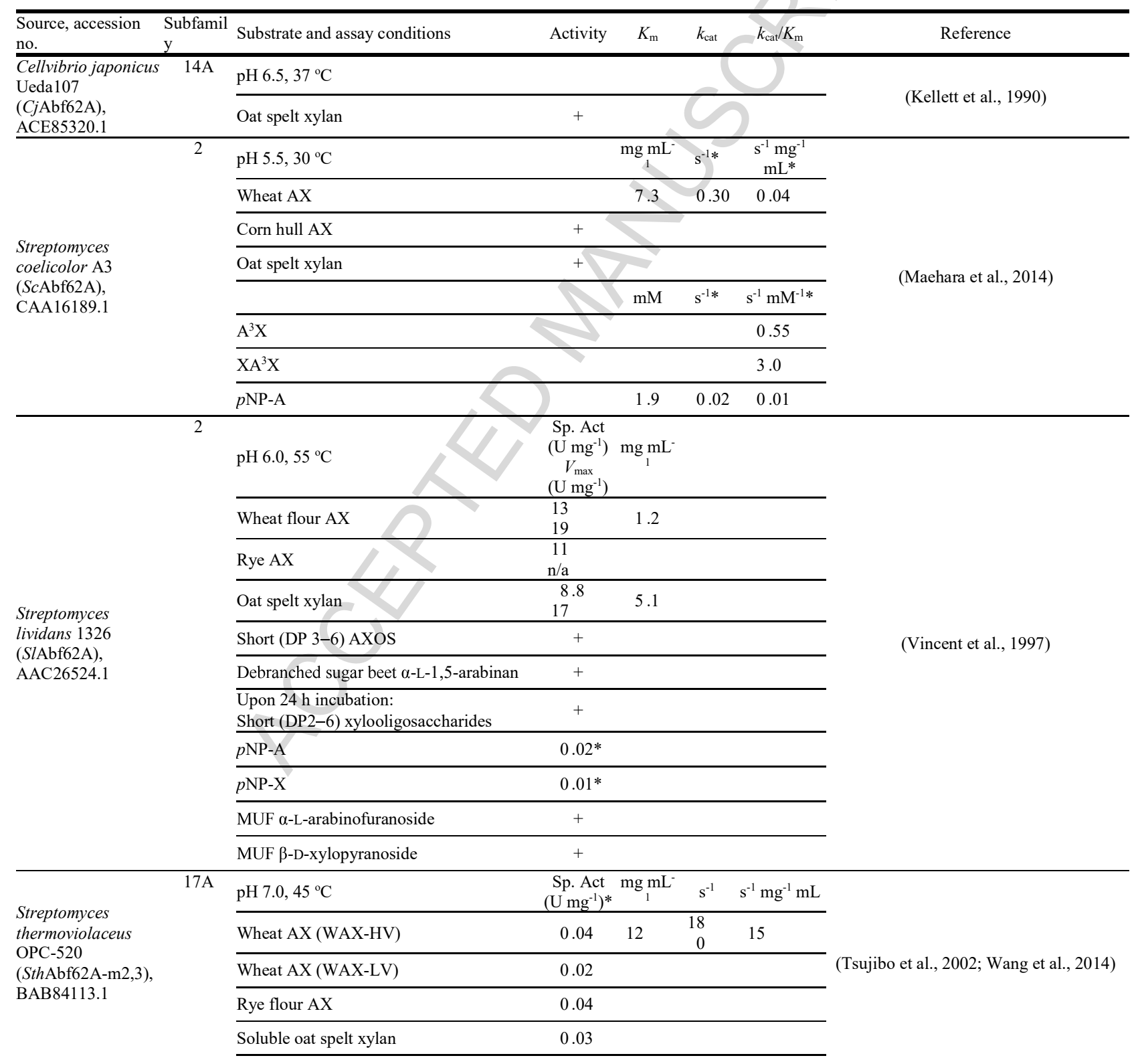




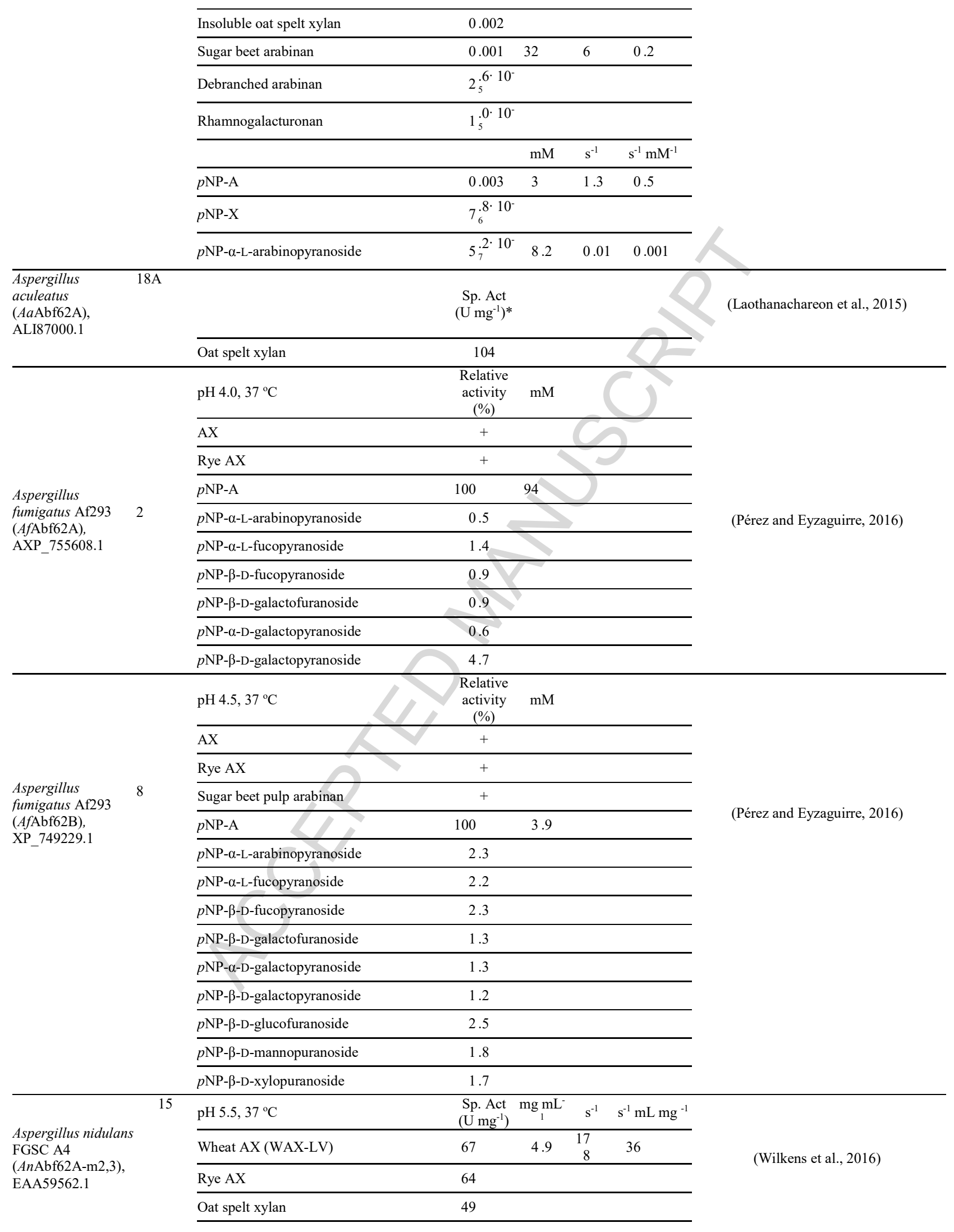




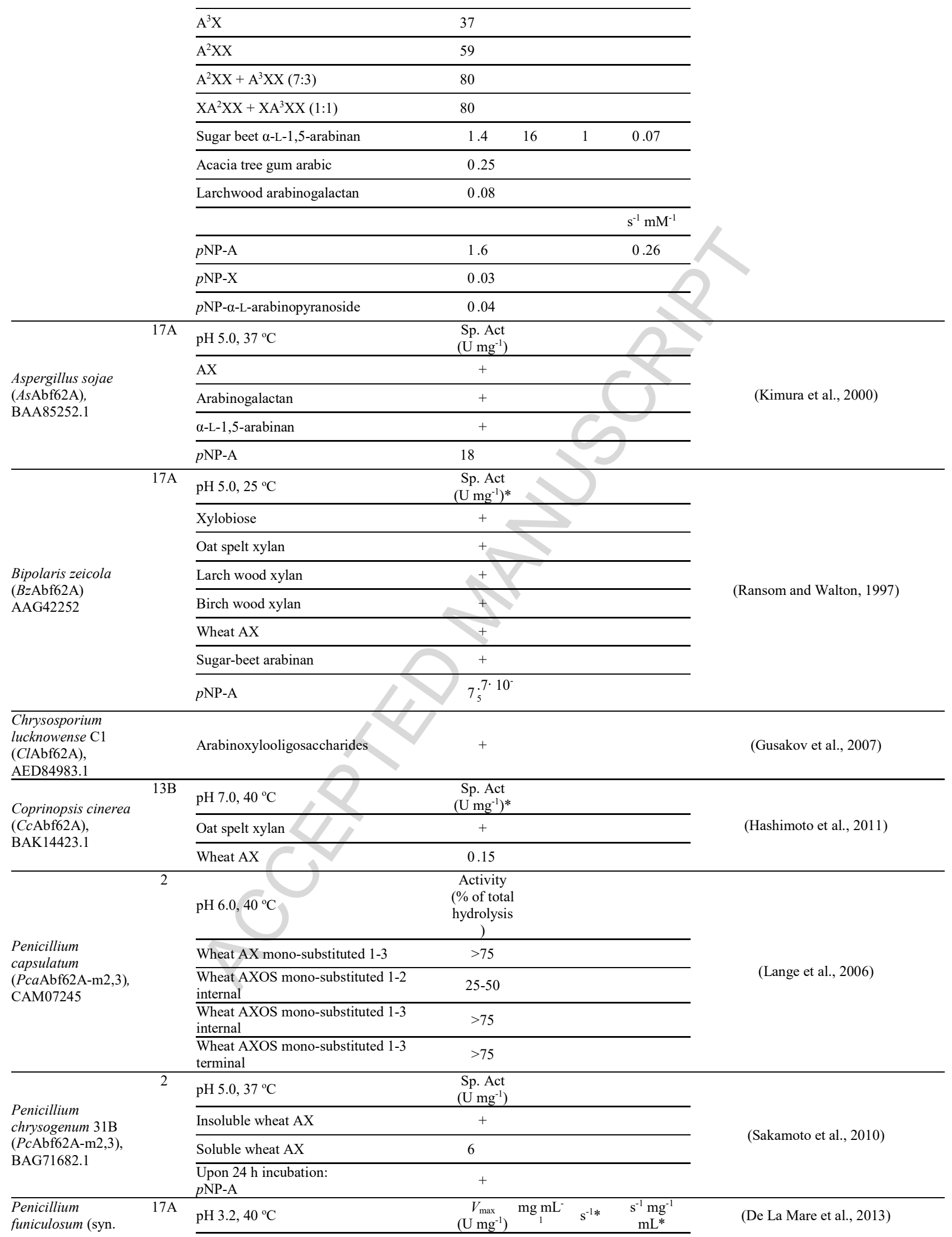




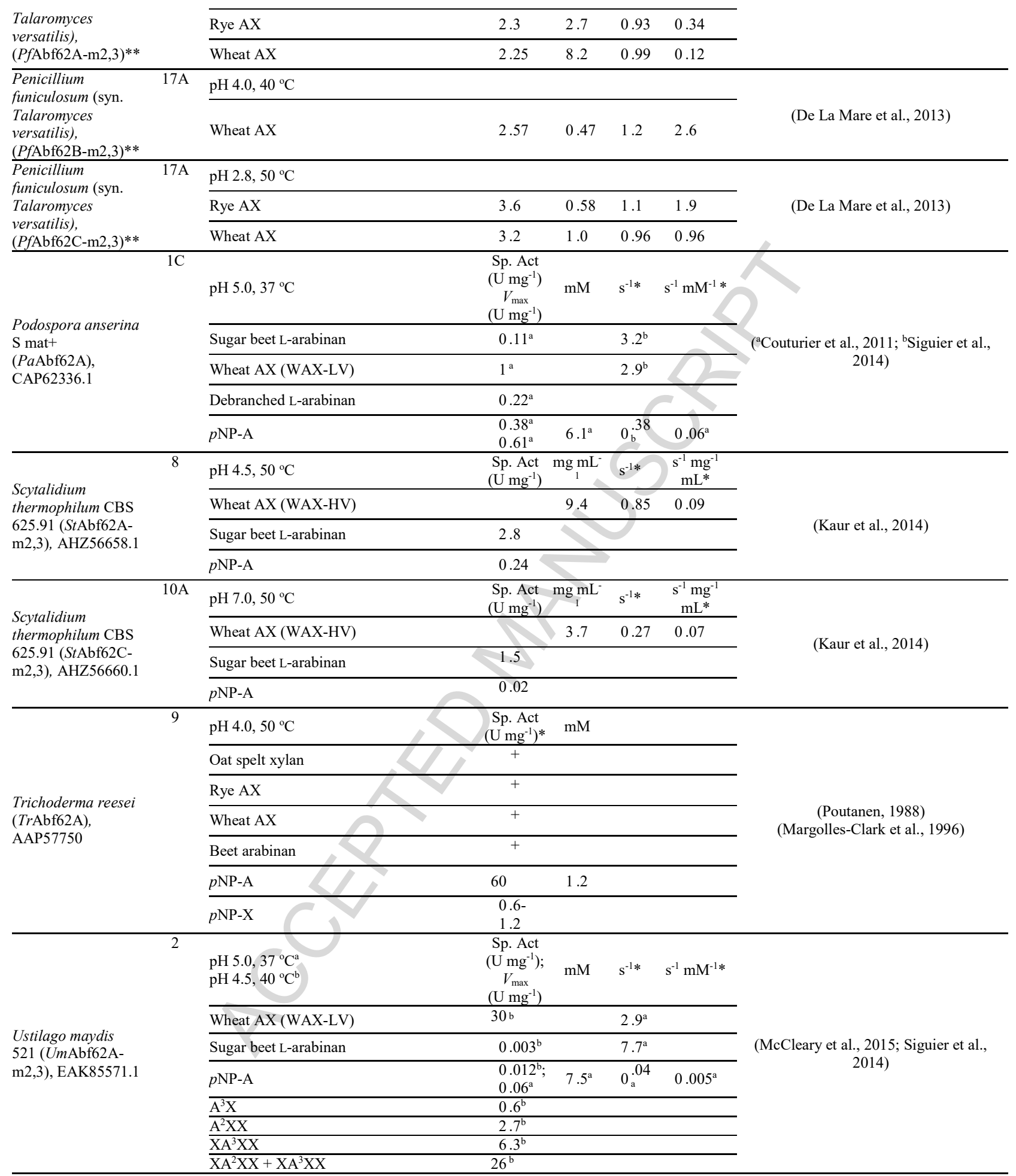


A

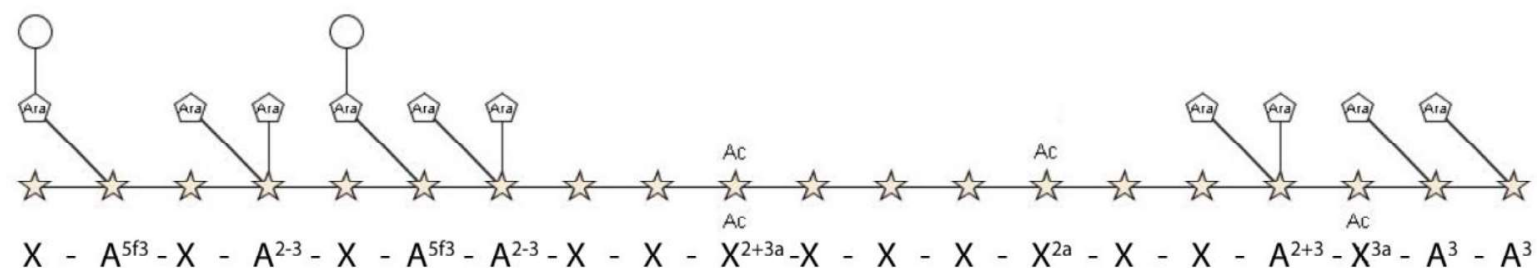

B

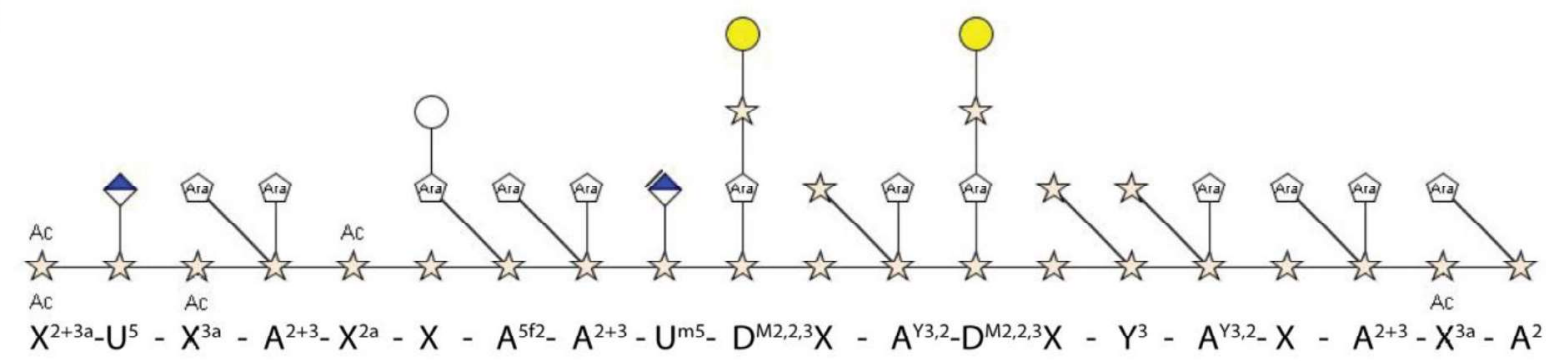

C

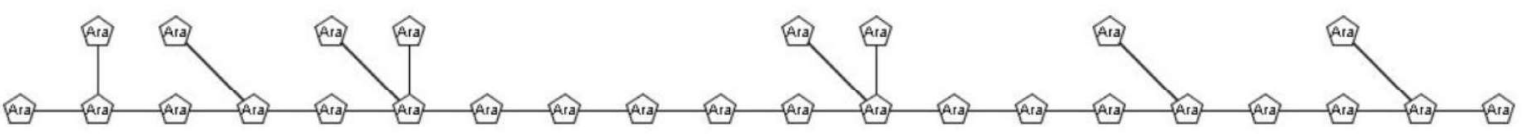

$A-A^{3}-A-A^{2}-A-A^{2+3}-A-A-A-A-A-A^{2+3}-A-A-A-A^{2}-A-A-A^{2}-A$
AC Acetyl (a)
$\diamond \quad 4-O-m e t h y l-D-g l u c u r o n i c$ acid $\left(U^{m}\right)$
is D-xylose $(\mathrm{X} / \mathrm{Y})$
$\diamond \quad$ D-glucuronic acid (U)
Ferulic acid (f) L-arabinose (A)
D-galactose (M)

Figure 1 


\section{ACCEPTED MANUSCRIPT}

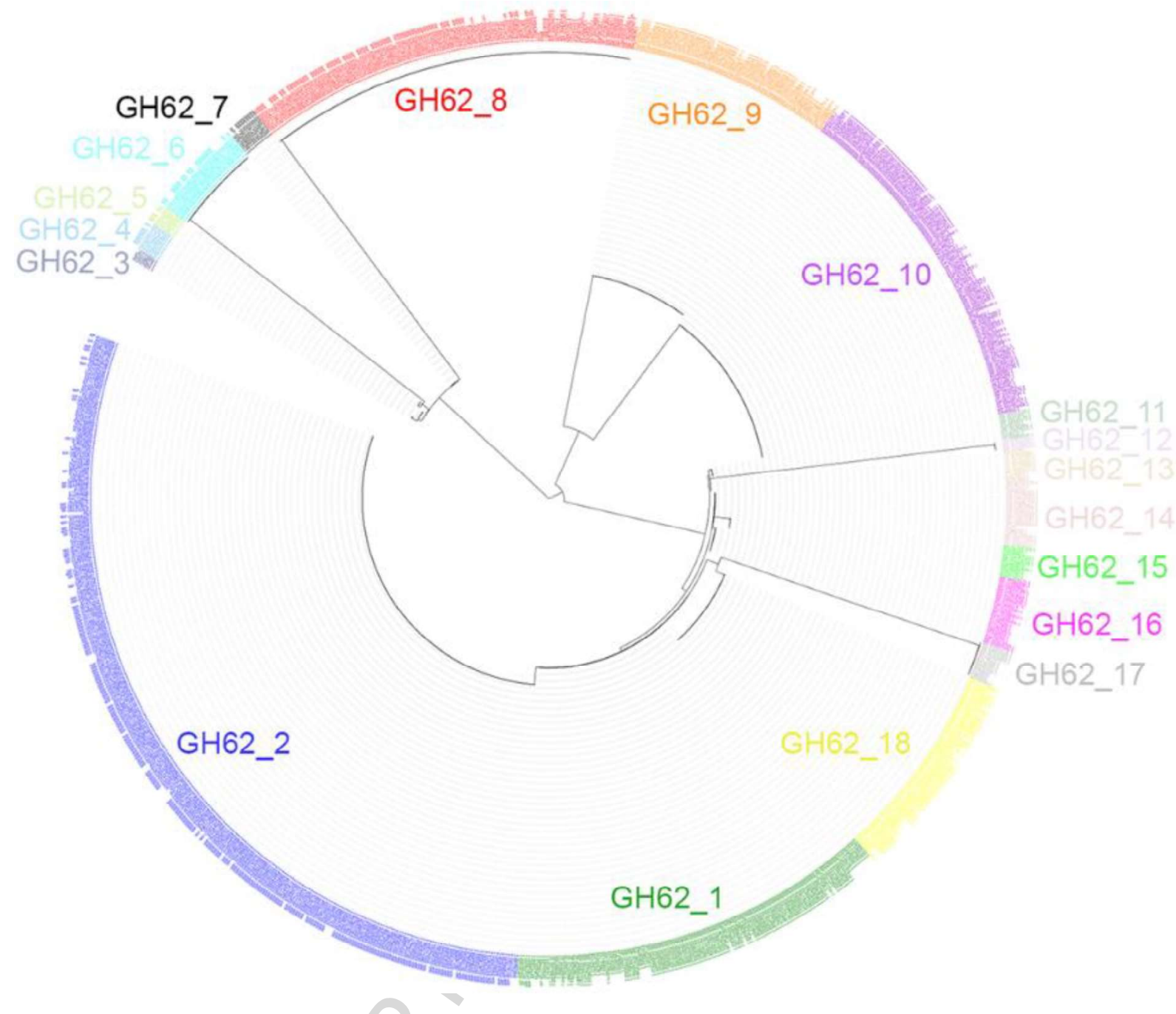

Figure 2

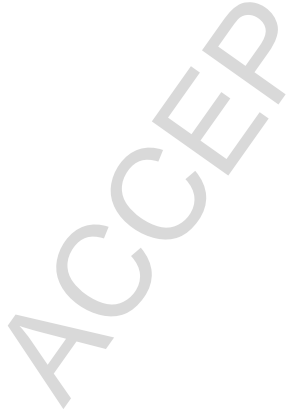



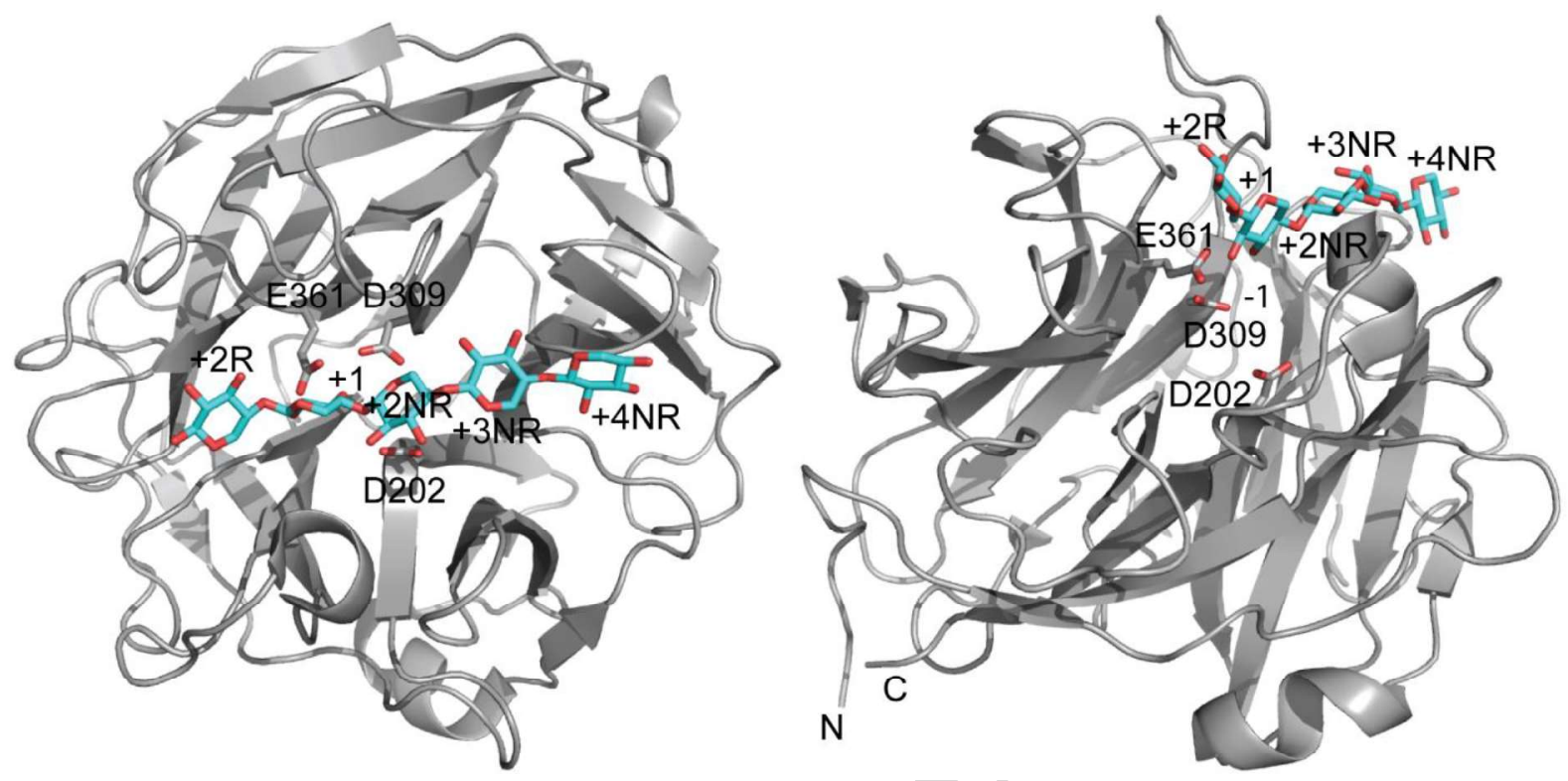

Figure 3 


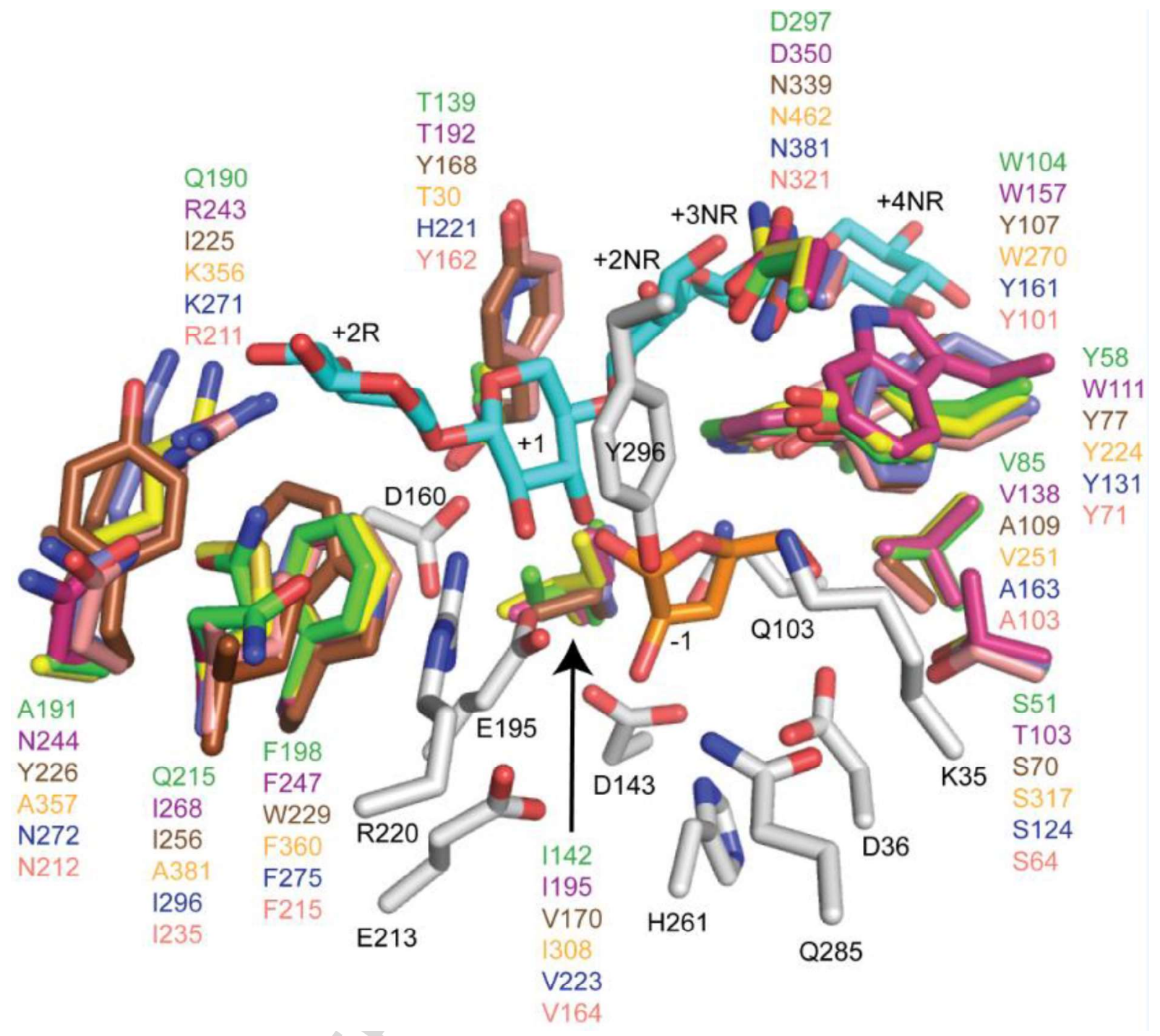

Figure 4 


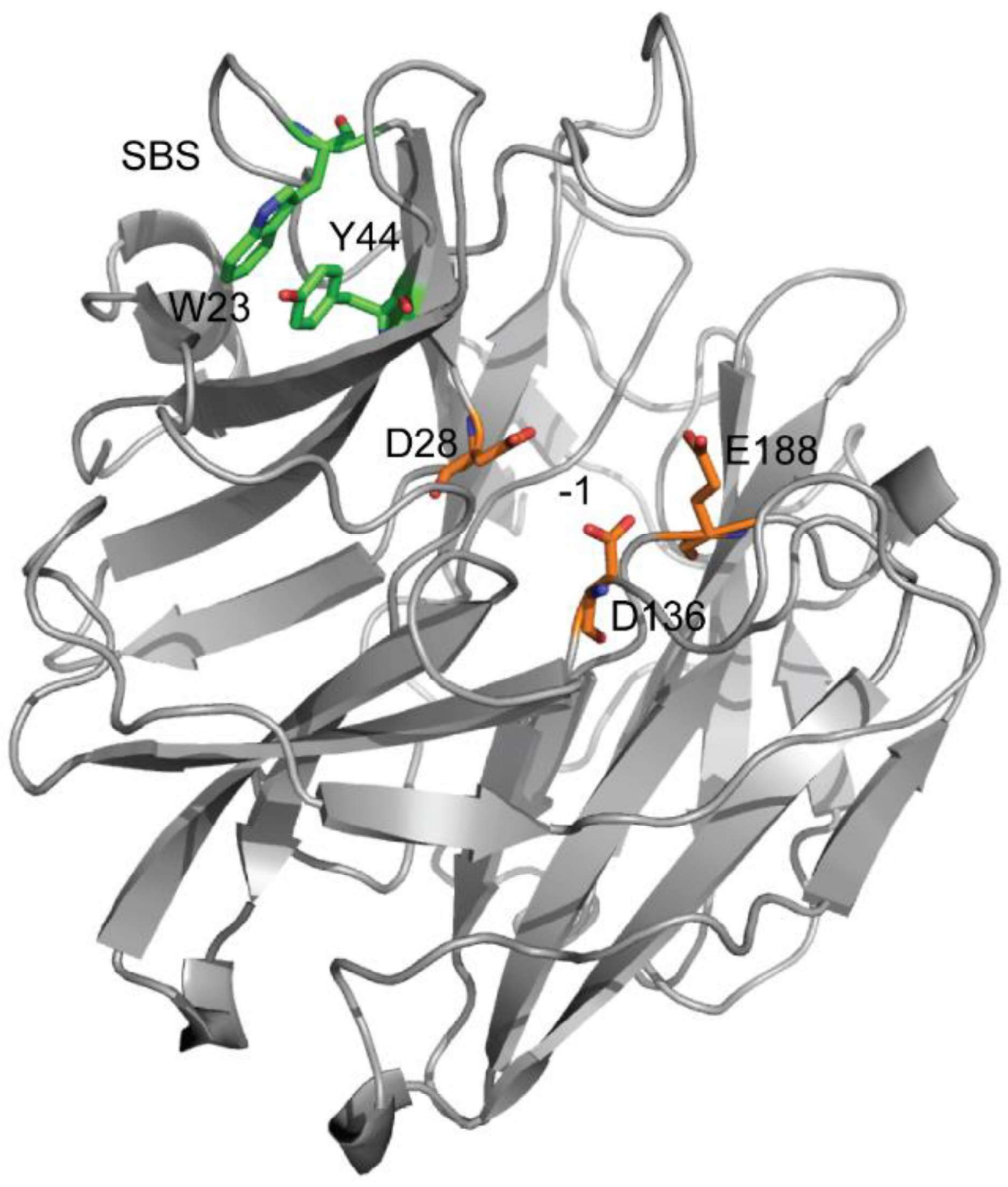

Figure 5 
Highlights

- Plant cell wall deconstruction requires several $\alpha$-L-arabinofuranosidases

- GH62 $\alpha$-L-arabinofuranosidases show significantly different substrate preference

- GH62 $\alpha$-L-arabinofuranosidases differ importantly in catalytic efficiency

- GH62 $\alpha$-L-arabinofuranosidases are abundant in fungal secretomes

- GH62 $\alpha$-L-arabinofuranosidases can act on recalcitrant biomass 